\title{
Metabolic Changes of Amino Acids and Flavonoids in Tea Plants in Response to Inorganic Phosphate Limitation
}

\author{
Santosh KC ${ }^{1,2}$, Meiya Liu ${ }^{2}$, Qunfeng Zhang ${ }^{2}$, Kai Fan ${ }^{2}$, Yuanzhi Shi ${ }^{2}$ and Jianyun Ruan ${ }^{2, *}$ \\ 1 Graduate School of the Chinese Academy of Agricultural Sciences (GSCAAS), Zhongguancun Nandajie, \\ Haidian, Beijing 100081, China; kcsntsh@hotmail.com \\ 2 Tea Research Institute (TRICAAS), 9 Meiling South Road, Hangzhou 310008, China; \\ liumeiya@tricaas.com (M.L.); hill@tricaas.com (Q.Z.); fankaitea@tricaas.com (K.F.); \\ shiyz@mail.tricaas.com (Y.S.) \\ * Correspondence: jruan@tricaas.com; Tel.: +86-571-86653938
}

Received: 12 October 2018; Accepted: 17 November 2018; Published: 21 November 2018

\begin{abstract}
The qualities of tea (Camellia sinensis) are not clearly understood in terms of integrated leading molecular regulatory network mechanisms behind inorganic phosphate (Pi) limitation. Thus, the present work aims to elucidate transcription factor-dependent responses of quality-related metabolites and the expression of genes to phosphate $(\mathrm{P})$ starvation. The tea plant organs were subjected to metabolomics analysis by GC $\times$ GC-TOF/MS and UPLC-Q-TOF/MS along with transcription factors and 13 metabolic genes by qRT-PCR. We found P starvation upregulated SPX2 and the change response of Pi is highly dependent on young shoots. This led to increased change in abundance of carbohydrates (fructose and glucose), amino acids in leaves (threonine and methionine), and root (phenylalanine, alanine, tryptophan, and tyrosine). Flavonoids and their glycosides accumulated in leaves and root exposed to P limitation was consistent with the upregulated expression of anthocyanidin reductase (EC 1.3.1.77), leucoanthocyanidin dioxygenase (EC 1.4.11.19) and glycosyltransferases (UGT78D1, UGT78D2 and UGT57L12). Despite the similar kinetics and high correlation response of Pi and SPX2 in young shoots, predominating theanine and other amino acids (serine, threonine, glutamate, valine, methionine, phenylalanine) and catechin (EGC, EGCG and CG) content displayed opposite changes in response to Pi limitation between Fengqing and Longjing-43 tea cultivars.
\end{abstract}

Keywords: Camellia sinensis; Inorganic phosphate; GC ×GC-TOF/MS; UPLC-Q-TOF/MS; qRT-PCR; ICP-AES

\section{Introduction}

Phosphorus is the second most limiting macronutrient for plant growth [1]. Inorganic phosphate (Pi) is a structural component of nucleic acids, phosphesters, and phospolipid. Pi has a vital role throughout cellular metabolisms and signal transduction cascades [2] that adjusts cell growth and development under specific nutritional conditions [3,4]. A complex array of morphological, physiological, and biochemical/metabolic adaptations to phosphorus starvation has been reported, coordinated to maximize internal Pi use and external Pi acquisition [5]. Morphologically, plants with deficient $P$ supply increases root surface area and root:shoot ratios for exploration of more soil volume. Changes in global gene expression, protein levels, and metabolite contents under P deficiency have been extensively studied [6-10]. Metabolic profiling studies revealed that $\mathrm{P}$ limitation leads to a reduction of phosphorylated metabolites, but an increase in carbohydrates, organic acids, amino acids, and nitrogenous compounds [9-13]. Notably, the balance between synthesis and catabolic carbon 
metabolism is disturbed under Pi-stress conditions, and P limitation frequently leads to upregulated expression of genes and accumulation of secondary metabolites phenylpropanoids, flavonoid and their glycosides, and anthocyanin [10,14]. Previous studies revealed that gene expression, including signaling response and metabolism, was tremendously changed by Pi starvation [15]. Transcription factor PHR1 is a major regulator of metabolic changes during P starvation [10]. The integral components of membrane $P H O 1$, phosphate and the small molecule transporter from root to shoot can trigger Pi export in ectopic plant cells [16]. In Arabidopsis, SPX, which is involved in phosphate ion transporter and cellular response to phosphate starvation, was weakly induced [17]. Likewise, in rice SPX2 was studied extensively in Pi sensing mechanism [18]. Previous studies have shown that there was a cross interaction effect between Pi deficiency and sugar signaling [19,20].

Tea (Camellia sinensis) is an important and widely consumed beverage globally. It is an important economic woody crop in Asian countries and P deficiency usually occurs in its growth environment, hence leading to a reduced production rate and deteriorated tea quality. The quality of tea, its taste and flavor are dependent on related constituents including amino acids and flavonoids, which are plant metabolites systematically regulated during growth and development of young shoots [21]. Furthermore, the metabolite flavonoids are additionally deemed to have health benefits to humans. Tea plants grow in acidic soil in which available P supply is usually inadequate due to low inherent content and strong fixation by abundant $\mathrm{Al}$ and Fe oxides. There have been several previous works concerning $P$ treatment in tea plants [22-26]. P deficiency impairs photosynthetic electron transport chain capacity and deteriorates tea sensory quality by decreasing the concentrations of total polyphenols, flavonoids, total free amino acids, and specific metabolites asparatate, theanine (Thea,) and glutamic acid [22,23]. Ding et al. [24] conducted correlations between mineral elements and metabolites induced by $\mathrm{P}$ deficiency and $\mathrm{P}$ excess, finding that $\mathrm{P}$ stress reduces the syntheses of flavonoids and phosphorylated metabolites. As in other plants, $P$ deficiency induces the accumulation of malate and citrate in the root and releases rhizosphere [25], which together with high P internal remobilization has been attributed to the tolerance mechanism of tea plants to low P supply [26]. Even though all these studies provided fundamental metabolite changes in response to different $P$ statuses in tea plants, it remains unknown in terms of the molecular regulatory network behind P deficiency. Hence, our study tended to elucidate the transcription factor-dependent response of quality-related metabolites and expression profiles of genes to phosphate $(\mathrm{P})$ starvation.

Teas of different types require variable characteristics of biochemical components in young shoots. For instance, young shoots suitable for green tea usually contain high free amino acids and relatively low catechins while those for black tea contain high contents of polyphenols and catechins. A selection of suitable varieties is a prerequisite to produce premium tea. In the present study, Fengqing Dayecha (Camellia sinensis var. assamica) which is suitable for black tea and Longjing-43 (Camellia sinensis var. sinensis) which is a good cultivar for green tea were chosen for P deficiency treatment. Untargeted metabolomics profiling based on GC $\times$ GC-TOF/MS and UPLC-Q-TOF/MS and in addition some targeted amino acid and catechins by High Performance Liquid Chromatography (HPLC) were used to investigate the change of metabolites in mature leaves, roots, and young shoots of tea plants to P starvation. To gain a deep understanding of the molecular mechanism, transcription factors and biosynthesis pathway genes were monitored in the meantime and collaboratively analyzed with metabolites. Our objectives were to gain systematical information on the response of quality-related metabolites (amino acids and flavonoids) and expression of genes to phosphorus starvation and genotypic variation of response among two cultivars suitable for different tea types.

\section{Results}

\subsection{Biomass and Pi Concentrations in Plants}

Tea plants of $+\mathrm{P}$ treatment contained higher concentrations of $\mathrm{Pi}\left(7.07 \mathrm{mg} \cdot \mathrm{g}^{-1}\right)$ than those of P-deficient $\left(2.56 \mathrm{mg} \cdot \mathrm{g}^{-1}\right)$. We observed large decreases of Pi concentration of the whole plant in 
Fengqing and Longjing-43 under P starvation (by $51 \%$ and $71 \%$, respectively) (Table 1 ). Biomass production was more depressed under P limitation $(22.82 \pm 7.1 \mathrm{~g})$ than in P-sufficient conditions $(28.46 \pm 7.6 \mathrm{~g})$, though the effect was not statistically significant (data not shown). The growth parameters of the root showed significant differences between the two P levels (Table 2) although there was no difference in biomass production (data not shown). Tea plants under P-starvation $(-\mathrm{P})$ conditions had significantly decreased root volume, surface area, and number of root tips but increased root length and root thickness in comparison to those in sufficient $(+\mathrm{P})$ treatment in Fengqing (Table 2).

Table 1. Concentrations of phosphorus $\left(\mathrm{mg} \cdot \mathrm{g}^{-1}\right)$ in plants supplied with two $\mathrm{P}$ levels in nutrient solutions.

\begin{tabular}{cccccc}
\hline Cultivar & P Level & Young Shoots & Leaves & Root & Whole Plant \\
\hline Fengqing & $-\mathrm{P}$ & $2.12 \pm 0.5 \mathrm{~b}$ & $2.39 \pm 1.31 \mathrm{~b}$ & $2.87 \pm 1.41 \mathrm{~b}$ & $2.46 \pm 1.04 \mathrm{~b}$ \\
Fengqing & $+\mathrm{P}$ & $3.80 \pm 0.8 \mathrm{a}$ & $3.94 \pm 0.83 \mathrm{a}$ & $7.17 \pm 2.66 \mathrm{a}$ & $4.97 \pm 1.41 \mathrm{a}$ \\
Longjing-43 & $-\mathrm{P}$ & $2.19 \pm 1.5 \mathrm{~b}$ & $3.81 \pm 1.00 \mathrm{~b}$ & $2.15 \pm 0.57 \mathrm{~b}$ & $2.72 \pm 0.93 \mathrm{~b}$ \\
Longjing-43 & $+\mathrm{P}$ & $12.05 \pm 5.63 \mathrm{a}$ & $7.15 \pm 2.16 \mathrm{a}$ & $9.15 \pm 2.44 \mathrm{a}$ & $9.45 \pm 3.33 \mathrm{a}$ \\
\hline
\end{tabular}

$\mathrm{a}$ and $\mathrm{b}$ within the column of the same cultivar indicate significant differences between $\mathrm{P}$ treatments $(p<0.05)$.

Table 2. Fold change of response to $P$ treatments $\left(\log _{2}[-\mathrm{P} /+\mathrm{P}]\right)$ in mean volume, surface area, length, average thickness, and tips of roots.

\begin{tabular}{ccc}
\hline Parameter & Fengqing & Longjing-43 \\
\hline Volume & $-1.54^{*}$ & $-2.84^{*}$ \\
Surface area & $-1.67^{*}$ & $-1.99^{*}$ \\
Number of root tips & $-1.96^{*}$ & $-0.77^{*}$ \\
Length & $2.32^{*}$ & $0.49^{*}$ \\
Average thickness & $0.15^{*}$ & $0.01^{\mathrm{NS}}$ \\
\hline
\end{tabular}

NS and * indicates insignificant or significant $(p<0.05)$ differences between the two P levels.

\subsection{Overview of Metabolomics Analysis of Tea Plants under $-P$ and $+P$ Conditions}

Partial Least Squares Distinguished Analysis (PLS-DA) was performed and the model was established using a response sequencing test of 20 permutations of 5 components variables $(-\mathrm{P}$ and $+\mathrm{P})$. The GC $\times$ GC-TOF/MS results showed that the $Q^{2}$ was 0.97 and average cumulative $R^{2}$ of $X$ and $Y$ of this model was 0.82 , with $0.13\left(\mathrm{R}^{2}\right)$ and $-0.53\left(\mathrm{Q}^{2}\right)$ values for intercepts on the $\mathrm{Y}$-axis. In addition, UPLC-Q-TOF/MS showed a similar phenomenon with $\mathrm{Q}^{2}$ of 0.89 . The average cumulative $\left(\mathrm{R}^{2}\right)$ of $\mathrm{X}$ and $Y$ for this model was 0.70 , and the intercepts on the $Y$-axis were $0.23\left(R^{2}\right)$ and $-0.54\left(Q^{2}\right)$, which indicated that the model was not over-fitting. To obtain a better regional difference and improve the effectiveness of the model and analytical ability, Orthogonality Partial Least Squares Distinguished Analysis (OPLS-DA) was performed. The GC $\times$ GC-TOF/MS model parameters of $\left(R^{2} X\right)$ and $\left(R^{2} Y\right)$ were 0.66 and 0.98 respectively and $\left(Q^{2}\right)$ was 0.98 . This showed that a $66.7 \%$ variation explained $98.9 \%$ difference between the treatments. Likewise, UPLC-Q-TOF/MS model parameters of $\left(R^{2} X\right)$ and $\left(R^{2} Y\right)$ were 0.56 and 0.98 respectively and $\left(Q^{2}\right)$ was 0.95 . Again, this showed that a $56.5 \%$ variation explained a $98.2 \%$ difference between the treatments. The predictive ability model of GC and UPLC were $82.8 \%$ and $77.35 \%$ and the difference values of $\left(\mathrm{R}^{2} \mathrm{Y}\right)$ and $\left(\mathrm{Q}^{2}\right)(\mathrm{cum})$ was less than 0.4. However, $\left(\mathrm{Q}^{2}\right)$ was greater than 0.5 that indicated a good predictive model to differentiate statistically cross verification of CV-ANOVA ( $p=0.00$ ) with significant treatment effect (Figure S1). The total number of profiled 39 primary and 36 secondary metabolites, where variable of importance in projection (VIP) $>1$ were identified and selected as metabolites altering significantly based on GC $\times$ GC-TOF/MS and UPLC Q-TOF/MS respectively (Figure S1, Tables S1 and S2). 


\subsection{Metabolomics Changes in Primary and Secondary Metabolites}

\subsubsection{Leaves}

In mature leaves, the phosphatases containing compounds, i.e., D-mannose-1-phosphate, decreased immensely ( $>23$-fold, $\log _{2}[-\mathrm{P} /+\mathrm{P}]$ ) in both cultivars (Figure 1 and Table S1). On the other hand, fructose (Fru) and glucose (Glc) in both cultivars highly accumulated ( $>24$-fold) in mature leaves of $-\mathrm{P}$ treatment. However, gluconate also accumulated to a less extent (0.2-3.1-fold) in both cultivars of -P treatment (Table S1). Threonine (Thr) and hydroxyproline increased by 22.7-23.1 and 23.6-26.8-fold, respectively in two cultivars with $-\mathrm{P}$ treatment. By contrast, in $-\mathrm{P}$ treatment Phenylalanine (Phe) increase or decrease constantly (0.6-fold) in Fengqing and Longjing-43, respectively. Asparagine (Asp) showed a high-fold decrease in Longjing-43 (24.1-fold) only. P starvation led to marked increases of butanoic acid (21.5-26.8-fold), pyruvate (Pyr) (6.6-24.8-fold) in both cultivars and benzenebutanoic acid in Longjing-43 only (24.1-fold). On the other hand, pentanedioic acid decreased by 27.7-27.9-fold in $-\mathrm{P}$ treatment of two cultivars. Ethanolamine (EA) decreased in Longjing-43 (27.1-fold) and Fengqing (4.6-fold) by $-\mathrm{P}$ treatment.

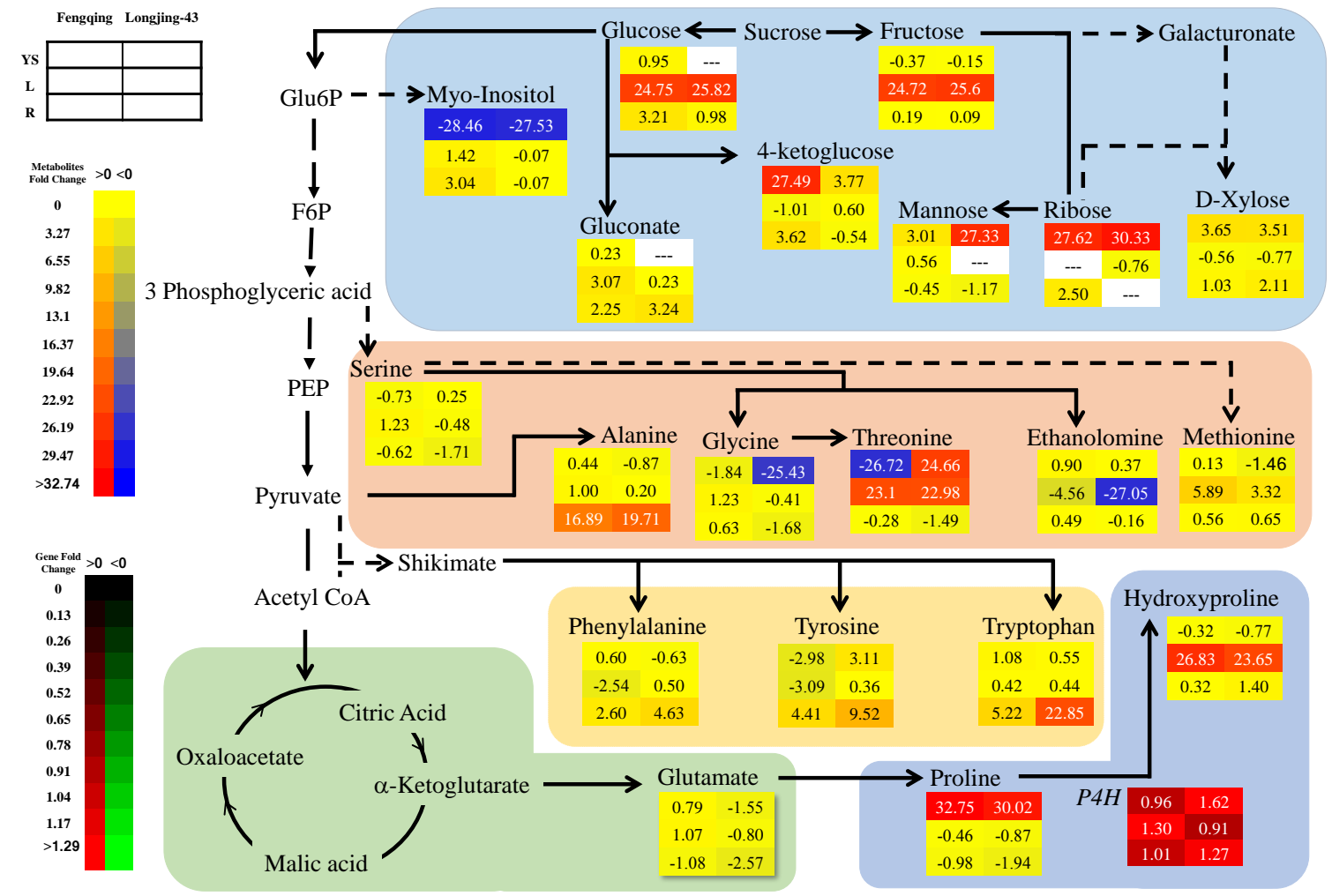

Figure 1. Fold change $\left(\log _{2}[-\mathrm{P} /+\mathrm{P}]\right)$ of primary metabolites and $P 4 H^{\mathrm{a}}$ in response to $\mathrm{P}$ starvation. Fengqing (left column) and Longjing-43 (right column) and from the top to the bottom rows are young shoots (first row), leaves (middle row) and root (button row). YS, L and R represents young shoots, leaves, and root, respectively. Metabolites and metabolic genes inside background color box represents different biosynthesis pathway. The solid arrow shows direct and dotted arrow represents speculated steps in the pathway. The data depicted from Table S1 and Table 5, positive as increase and negative as decrease in fold change. On the false color scale red indicates increase; blue and green indicates decrease in metabolites and gene. ${ }^{a} \mathrm{P} 4 \mathrm{H}$ means prolyl 4-hydroxylase.

The response of secondary metabolites in mature leaves to $\mathrm{P}$ deficiency was largely variable among cultivars (Figure 2 and Table S2). P starvation increased luteolin-7-O glucoside (13- and 14-fold) and delphinidin (12.2- and 1.4-fold) in Fengqing and Longjing-43, respectively. A few flavonoids were 
specifically elevated by P limitation in cultivar, for example cyanidin (15.1-fold), epigallocatechin (EGC; 21.5-fold), rutin (15.7-fold) in Longjing-43, and isoquercitrin (14.2-fold) and procyanidin B1 (9.5-fold) in Fengqing. By contrast, P starvation led to decreases of $4^{\prime}$-methoxychalcone (3.7-3.8-fold), gallic acid (0.3-1.0-fold) in both cultivars, kaempferol-3-O-glucoside (6.2-fold) in Longjing-43, m-trigallic acid (15.1-fold), quercetin-3,4'-diglucoside (12.2-fold) in Fengqing.



Figure 2. Fold change $\left(\log _{2}[-\mathrm{P} /+\mathrm{P}]\right)$ of secondary metabolites and metabolic genes in response to $\mathrm{P}$ starvation. Fengqing (left column) and Longjing-43 (right column) and from the top to the bottom rows are young shoots (first row), leaves (middle row) and root (button row). YS, L and R represents young shoots, leaves, and root, respectively. Metabolites and metabolic genes inside background color box represents different biosynthesis pathway. The solid arrow shows direct and dotted arrow represents speculated steps in the pathway. The data depicted from Table S2 and Table 5, positive as increase and negative as decrease in fold change. On the false color scale red indicates increase; blue and green indicates decrease in metabolites and gene. ANR, anthocyanin reductase; LDOX, leucoanthocyanidin dioxygenase; UGT57L12, flavanol 7-O glycosyltransferase; UGT78D2, flavanol 3-O-glucosyltransferase 2; UGT78D1, flavanol 3-O-glycoside L-rhamnosyl transferase 1.

\subsubsection{Root}

The change of phosphates in root was less marked than that in mature leaves (Figure 1 and Table S1). P starvation led to a slight decrease of Frucose-6-phosphate (Fru6P; 0.2-1.4-fold), Glucose-6-P (Glc6P; 0.2-1.9-fold) and D-myo-inisitol-1 phosphate (0.6-1.7-fold) but increased D-erythro-Pentofuranose phosphate (0.4-0.7-fold) (Table S1). P deficiency moderately increased Glc (1-3.21-fold), D-xylose (1-2.1-fold) and gluconate (2.2-3.2-fold) in two cultivars, and ribose in Fengqing (2.5-fold). P starvation led to high increases of alanine (Ala) (16.9-20-fold), tryptophan (Trp) (5.2-22.8-fold) and tyrosine (Tyr) (4.4-9.5-fold) in two cultivars.

$\mathrm{P}$ starvation immensely increased quinic acid (2.1-14.5-fold), shikimic acid (13.0-14-fold), epiafzelechin-epicatechin 3,3'-digallate (1.9-15.4-fold), diosmetin 7-O-beta-D-glucuronopyranoside (13.2-17.8-fold), kaempferol 3- $\beta$-D-glucopyranoside (0.6-20.1-fold), tricin 7-glucuronide (0.3-16.2-fold) 
and prunin 6"-p-coumarate (18.1-19.0-fold) but decreased 2,4-dihydroxybenzoic acid (14.8-17.4-fold) in two cultivars (Figure 2 and Table S2).

\subsubsection{Young Shoots}

Phosphorus containing compounds in young shoots changed inconsistently among cultivars (Figure 1 and Table S1). Fru6P decreased in cv. assamica (Fengqing 30.9-fold) but increased in cv. sinensis (Longjing-43; 27.1-fold). Glc6P decreased in Fengqing (6.8-fold) but increased in Longjing-43 (5.5-fold). Myo-insitol-1-phosphate and erythro-pentofuranose phosphate increased in both cultivars and most remarkably in Fengqing. P starvation moderately increased carbohydrate D-xylose in Fengqing and Longjing-43 (3.5-3.6-fold), tremendously ribose (27.6 and 30.3-fold), and high mannose (27.3-fold) in Longjing-43. By contrast, P deficiency increased 4-ketoglucose by 27.5- and 3.8-fold and 2-ketoglutarate by 26.1- and 27.2-fold in Fengqing and Longjing-43, respectively. With P limitation, myo-inositol, derived from Glc6P, decreased in Fengqing (28.5-fold) and Longjing-43 (27.5-fold). Phosphorus deficiency caused significant changes of amino acids in young shoots. Thr was reduced in Fengqing (26.7-fold) but increased in Longjing-43 (24.7-fold) by Pi starvation. Phe was mildly decreased in Longing-43 (0.6-fold) only. Remarkably, isoleucine (Ile) and proline (Pro) increased by 25.1-27.3-fold and 30.0-32.8-fold, whereas glycine (Gly) and leucine (Leu) decreased by 1.8-25.4 and 28.7-29.9 in both cultivars (Table S1).

$\mathrm{P}$ starvation significantly affected the accumulation of secondary metabolites (Figure 2 and Table S2). The uniformly increased secondary metabolites in both cultivars tremendously changed isoquercitrin (7.0-18.0-fold), epiafzelechin-epicatechin 3,3'-digallate (3.0-8.4-fold), quercetin 3-glucoside (2.0-4.3-fold), quercetin -( $2^{\prime \prime}$-galloyl- $\alpha$-L-arabinopyranoside) (3.1-15.6-fold), m-trigallic acid (1.1-2.3-fold) and those mildly changed delphinidin (0.9-2.2-fold), catechin (0.99-1.1-fold) and epigallocatechin gallate (EGCG, 0.9-1.0-fold). On the other hand, P starvation decreased procyanidin B1 (2.1-4), prunin 6"-p-coumarate (1.1-2.0-fold), kaempferol 3-sophoroside 7-glucuronide (0.4-15.2-fold), quercetin-3-sulfate (0.3-1.4-fold) and chalcone (4'-methoxychalcone and $4,2^{\prime}, 4^{\prime}$,alpha-tetrahydroxydihydrochalcone) (6.9-20.3-fold). However, there were different responses among cultivars. For example, under low P supply, rutin, kaempferol-3-O-glucoside, (-)-Epigallocatechin 3,3'-di-gallate and catechol decreased in Longjing-43 but increased in Fengqing (Table S2).

Due to their important role influencing tea quality, the fold changes of delphindin, EGC, glutamine (Gln) and quercetin-3-glucoside in young shoots were selected and subject to Pearson's correlation analysis with other metabolites to screen the most related metabolites based on each cultivar (Figure 3). The results indicate that delphinidin which was mildly induced in Fengqing by P deficiency significantly and positively correlated with Phe but negatively with glucose (Glc), Thr, Tyr and Ile. Interestingly, there was significantly strong and negative correlation between EGC and epiafzelechin-epicatechin 3,3'-digallate. The secondary metabolites, quercetin 3-glucoside, have a significant and positive correlation with cyanidin and rutin. In addition, the major amino acid Gln had positive and almost similar fold change correlation with D-xylose and Phe but weakly and negatively correlated with Ala.

Young shoots of Longjing- 43 and delphinidin had positive correlation with rutin and quercetin while negatively with EGC and tectorigenin 7-sulfate (Figure 3). EGC had strong and negative correlations with delphinidin, cyanidin, procyanidin B1, quercetin 3,4'-diglucoside and quercetin 3-glucoside. Likewise, quercetin 3-glucoside showed a strong and positive correlation with anthocyanin-related compounds (delphinidin, cyanidin, quercetin 3,4 diglucoside and paratocarpin A). Gln showed positive correlation with D-xylose, Phe and 2-ketoglutarate and negative ones with gluconate, Thr, and Ala. 


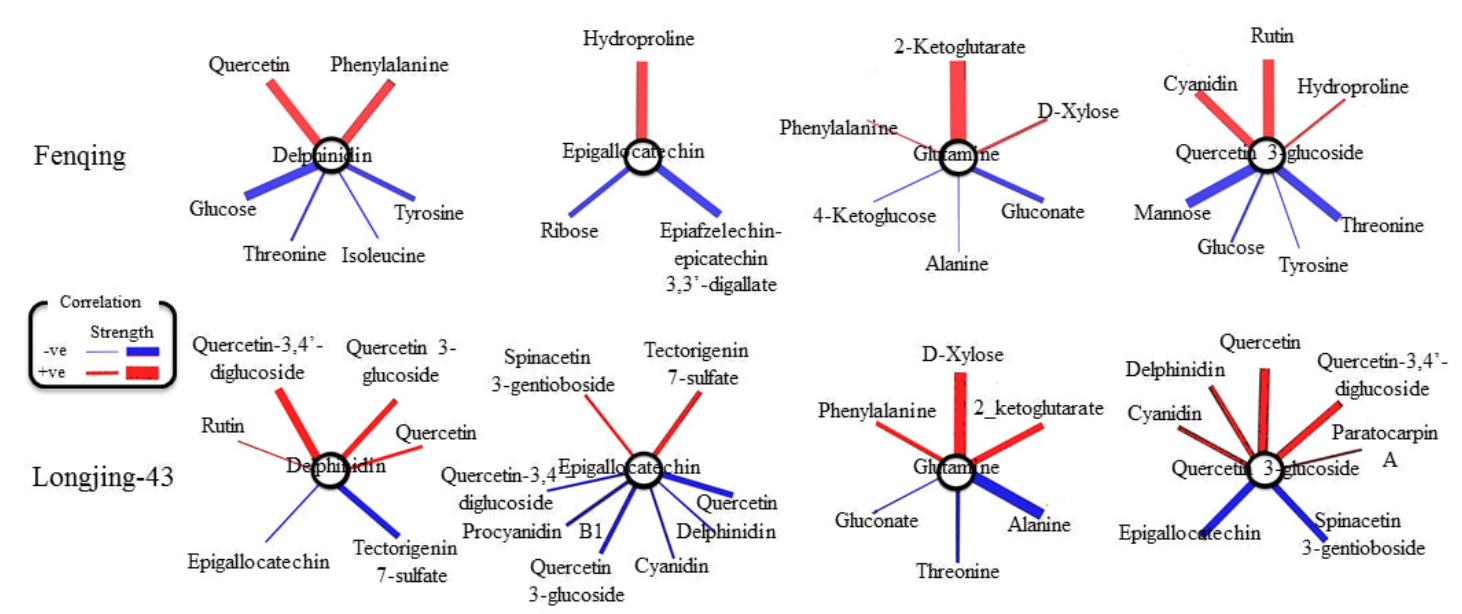

Figure 3. Correlations between fold change $\left(\log _{2}[-\mathrm{P} /+\mathrm{P}]\right)$ of selected significantly changed $(p<0.05$, $t$-test) metabolites in young shoots of Fengqing and Longjing-43. Red and blue colors indicate positive and negative coefficients and line thickness indicate correlation strength.

\subsection{Targeted Analysis of Amino Acids and Catechins in Young Shoots}

Young shoots are the harvestable plant organ for made tea production. The quality-related components, i.e., free amino acids and catechins in young shoots then were further quantified by targeted analysis (Table 3). Most of the free amino acid concentration in young shoots were significantly changed by $-\mathrm{P}$ treatment (Table 3). Asp, Gly and Leu were significantly decreased (19-76\%) while Pro and Ile significantly increased (51-71\%) by $-\mathrm{P}$ treatment in both cultivars. However, some other amino acids responded to $-\mathrm{P}$ treatment differently between the two cultivars. Glutamate, Val, Met and Phe increased (78-81\%) in Fengqing but decreased in Longjing-43 (44-75\%) whereas Thea, Serine (Ser) and Thr decreased in Fengqing but increased in Longjing-43 under P starvation. Arg and Tyr significantly increased only in Fengqing and Longjing-43, respectively by P deficiency. Other amino acids (His, Ala, Cys and Lys) was not affected by $-\mathrm{P}$ treatment. Fengqing contained a higher concentration of Glu than Longjing-43. The relative composition of free amino acids in Fengqing was changed, showing that Thea predominated in P-sufficient young shoots while Glu and Thea became the two major compound by $-\mathrm{P}$ treatment. In Longjing-43, Thea predominated in the pool of free amino acids regardless of $\mathrm{P}$ status. The concentrations of catechins in young shoots were affected by $\mathrm{P}$ treatment differently in the two cultivars. EGCG is the main catechin in young shoots and was affected (increase by $32 \%$ ) by $-\mathrm{P}$ treatment only in Fengqing. EGC, ECG and GC increased (61-83\%) in Fengqing but decreased (by 28 and $82 \%$ ) in Longjing-43. Only catechin increased (62-70\%) in both cultivars. 
Table 3. Targeted metabolites amino acid and catechins (mg.g-1) in young shoots of tea plants supplied with two P levels in nutrient solutions.

\begin{tabular}{|c|c|c|c|c|}
\hline \multirow{2}{*}{ Metabolites } & \multicolumn{2}{|c|}{ Fengqing } & \multicolumn{2}{|c|}{ Longjing-43 } \\
\hline & $-\mathbf{P}$ & $+P$ & $-\mathbf{P}$ & $+P$ \\
\hline \multicolumn{5}{|l|}{ Amino acids } \\
\hline Asp & $2.06 \pm 0.16 b$ & $3.13 \pm 0.05 a$ & $1.36 \pm 0.05 b$ & $2.47 \pm 0.22 \mathrm{a}$ \\
\hline Gly & $0.29 \pm 0.01 b$ & $1.55 \pm 0.14 \mathrm{a}$ & $0.11 \pm 0.01 b$ & $0.47 \pm 0.04 a$ \\
\hline Leu & $0.28 \pm 0.01 b$ & $0.45 \pm 0.04 a$ & $0.11 \pm 0.01 b$ & $0.20 \pm 0.01 a$ \\
\hline Pro & $3.56 \pm 0.13 a$ & $1.95 \pm 0.04 b$ & $1.66 \pm 0.13 a$ & $0.84 \pm 0.01 b$ \\
\hline Ile & $1.21 \pm 0.05 a$ & $0.86 \pm 0.08 b$ & $0.43 \pm 0.02 \mathrm{a}$ & $0.22 \pm 0.02 b$ \\
\hline Glu & $9.64 \pm 0.77 a$ & $7.78 \pm 0.13 b$ & $2.36 \pm 0.19 b$ & $3.41 \pm 0.06 a$ \\
\hline Val & $0.42 \pm 0.01 \mathrm{a}$ & $0.55 \pm 0.05 b$ & $0.46 \pm 0.02 b$ & $0.62 \pm 0.06 a$ \\
\hline Met & $2.52 \pm 0.10 \mathrm{a}$ & $1.97 \pm 0.78 b$ & $1.08 \pm 0.04 b$ & $1.44 \pm 0.3 \mathrm{a}$ \\
\hline Phe & $1.19 \pm 0.05 a$ & $0.93 \pm 0.01 b$ & $0.52 \pm 0.02 b$ & $1.18 \pm 0.2 \mathrm{a}$ \\
\hline Thea & $8.52 \pm 0.68 b$ & $20.81 \pm 0.36 a$ & $22.78 \pm 1.83 a$ & $17.02 \pm 0.29 b$ \\
\hline Ser & $0.16 \pm 0.02 b$ & $0.31 \pm 0.03 a$ & $0.20 \pm 0.02 \mathrm{a}$ & $0.12 \pm 0 \mathrm{~b}$ \\
\hline Thr & $0.24 \pm 0.01 b$ & $0.38 \pm 0.34 a$ & $0.78 \pm 0.03 a$ & $0.55 \pm 0.05 b$ \\
\hline Arg & $1.18 \pm 0.05 a$ & $0.78 \pm 0.01 b$ & $0.41 \pm 0.35^{\mathrm{NS}}$ & $0.24 \pm 0.25$ \\
\hline Tyr & $0.21 \pm 0.15^{\mathrm{NS}}$ & $0.43 \pm 0.01$ & $0.45 \pm 0.05 a$ & $0.24 \pm 0.03 b$ \\
\hline His & $0.59 \pm 0.17^{\mathrm{NS}}$ & $0.52 \pm 0.13$ & $0.55 \pm 0.14^{\mathrm{NS}}$ & $0.53 \pm 0.18$ \\
\hline Ala & $0.11 \pm 0.02^{\mathrm{NS}}$ & $0.08 \pm 0.01$ & $0.08 \pm 0.04^{\mathrm{NS}}$ & $0.11 \pm 0.03$ \\
\hline Cys & $0.40 \pm 0.25^{\mathrm{NS}}$ & $0.49 \pm 0.36$ & $0.29 \pm 0.08^{\mathrm{NS}}$ & $0.56 \pm 0.37$ \\
\hline Lys & $0.81 \pm 0.49^{\mathrm{NS}}$ & $1.72 \pm 1.02$ & $0.61 \pm 0.39 \mathrm{NS}$ & $1.17 \pm 0.51$ \\
\hline \multicolumn{5}{|l|}{ Catechins } \\
\hline EGCG & $34.03 \pm 1.36 a$ & $25.77 \pm 2.34 b$ & $33.25 \pm 6.5^{\mathrm{NS}}$ & $36.44 \pm 0.4$ \\
\hline EGC & $6.92 \pm 0.56 a$ & $4.25 \pm 0.07 \mathrm{~b}$ & $3.02 \pm 0.24 b$ & $10.93 \pm 0.19 a$ \\
\hline ECG & $2.71 \pm 0.22 \mathrm{a}$ & $2.24 \pm 0.04 b$ & $2.80 \pm 0.22 b$ & $3.40 \pm 0.06 a$ \\
\hline GC & $0.14 \pm 0.05 a$ & $0.03 \pm 0.02 b$ & $0.05 \pm 0^{\mathrm{NS}}$ & $0.07 \pm 0.03$ \\
\hline CG & $0.03 \pm 0 b$ & $0.05 \pm 0.01 \mathrm{a}$ & $0.06 \pm 0.01 \mathrm{a}$ & $0.02 \pm 0 b$ \\
\hline $\mathrm{C}$ & $1.06 \pm 0.04 \mathrm{a}$ & $0.66 \pm 0.06 b$ & $1.37 \pm 0.04 a$ & $0.96 \pm 0.19 b$ \\
\hline GCG & $0.19 \pm 0.04^{\mathrm{NS}}$ & $0.20 \pm 0.02$ & $0.23 \pm 0.01^{\mathrm{NS}}$ & $0.16 \pm 0.03$ \\
\hline
\end{tabular}

Means with different letter and NS indicates significant or not significant $(p<0.05)$ differences between $\mathrm{P}$ treatments.

\subsection{Response of Pi-Dependent Transcription Factors and Metabolic Genes to P Conditions}

\subsubsection{Pi-Dependent Gene Transcriptional Expression}

Table 4 shows the fold changes in expression of transcription factors of PHR1, PHO1 and SPX2. We found that all these genes were upregulated in both cultivars. The upregulation was within the comparable ranges among organs (young shoots, leaves, and root). However, their expression was more upregulated in the young shoots than in leaves and root. There were significant linear correlations between the $\log _{2}$ fold change ratio $(-\mathrm{P} /+\mathrm{P})$ of PHR1, PHO1 and SPX2 with those of Pi concentrations in most cases (Figure 4). It appeared that the transcription factor SPX2 was more dependent on Pi in comparison to PHR1 and PHO1.

Table 4. qRT-PCR expression of transcription factor genes normalize with reference gene delta-CT $\left(\Delta C_{T}\right)$ are shown as fold changes $\left(\log _{2}[-\mathrm{P} /+\mathrm{P}]\right)$.

\begin{tabular}{ccccccc}
\hline \multirow{2}{*}{ Genes } & \multicolumn{3}{c}{ Fengqing } & \multicolumn{3}{c}{ Longjing-43 } \\
\cline { 2 - 7 } & Young Shoots & Leaves & Root & Young Shoots & Leaves & Root \\
\hline PHR1 & $0.89^{* * *}$ & $1.03^{*}$ & $0.69^{*}$ & $0.01^{*}$ & $0.95^{*}$ & $0.86^{* *}$ \\
PHO1 & $1.01^{*}$ & $1.21^{\mathrm{NS}}$ & $0.70^{*}$ & $0.81^{\mathrm{NS}}$ & $0.78^{*}$ & $1.20^{* * *}$ \\
SPX2 & $1.70^{* *}$ & $1.21^{*}$ & $1.53^{* * *}$ & $1.76^{* * *}$ & $0.82^{* * *}$ & $0.55^{* * *}$ \\
\hline
\end{tabular}

NS, ${ }^{* * *}, \overline{* *}$ and $*$ indicate not significant or significance at $0.001,0.01$, and 0.05 levels between $P$ treatments by $t$-test, respectively. 

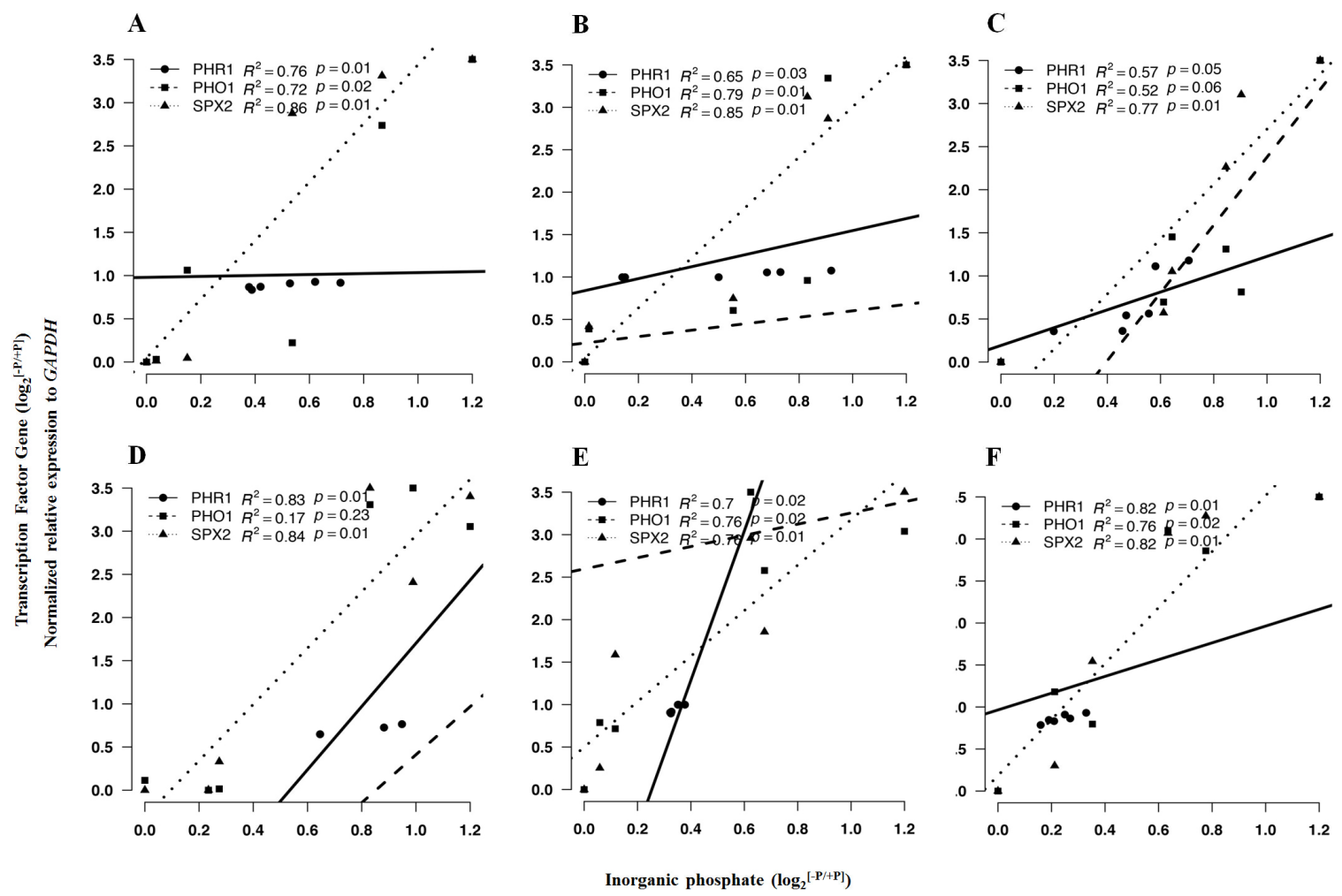

Figure 4. Linear correlations between the fold changes $\left(\log _{2}[-\mathrm{P} /+\mathrm{P}]\right)$ of PHO1, PHR1 and SPX2. The expression of Pi concentration in young shoots $(\mathbf{A}, \mathbf{D})$, leaves $(\mathbf{B}, \mathbf{E})$ and $\operatorname{root}(\mathbf{C}, \mathbf{F})$ of cultivars Fengqing (A-C) and Longjing-43 (D-F).

\subsubsection{Expression of Selected Genes in Response to P Limitation}

The expression of most genes investigated was upregulated in all organs of two cultivars though in some cases not statistically significant (Table 5). Amino acid transferase 1 (BCAT1, EC 2.6.1.42) catalyses the last step, Val and Leu synthesis from Pyr (Figure 1). BCAT1 expression was upregulated by $\mathrm{P}$ starvation in all plant organs of Fengqing $(>0.85$-fold) and Longjing-43 ( $>0.85$-fold). Biosynthesis of Phe from arogenate route in plants is primarily catalyst by arogenate dehydratase 1 (ADT1, EC 4.2.1.51/4.2.1.91). There was a significant upregulation effect on ADT1 by $-\mathrm{P}$ treatment in all organs of both cultivars except in Longjing- 43 root. Met biosynthesis was catalyzed by methyltransferase 2 (MS2, EC 2.1.1.14) from homocysteine. MS2 expression was upregulated in young shoots of both cultivar and root of Fengqing as a result of P starvation. Likewise, NADH-GOGAT (GLT1) was upregulated in leaves of all cultivars. The exchange between 2-oxoglutarate and 2-oxoglutamate was catalyzed by $\omega$-amidase, chloroplast (NPL3, EC 3.5.1.111). Remarkably, the expression of NPL3 was significantly upregulated in root and young shoots. The biosynthesis of hydroxyproline from Pro is primarily catalyst by prolyl 4-hydroxylase ( $P 4 H$, EC 1.14.11.2). The expression of $P 4 H$ was significantly upregulated by $P$ starvation in leaves and young shoots.

The final two steps of flavonoid biosynthesis resulting in the formation of EGC and EC were catalyzed by anthocyanidin reductase (ANR, EC 1.3.1.77) (Figure 2). ANR expression in young shoots was not affected but was significantly upregulated in roots of both cultivars (Table 5). Leucoanthocyanidin dioxygenase (LDOX, EC 1.4.11.19) which synthesizes leucocyanidin from cyanidin was upregulated in young shoots in Longing-43 cultivar only. During flavone and flavanol biosynthesis, glycosylation occurs in O-3 or O-7 position, which is assumed to be catalyzed by UGT78D family (UGT78D1; EC 2.4.1.159, UGT78D2; EC 2.4.1.91) and UGT57L12, EC 2.1.4.81), respectively. The expression of these UGT genes was upregulated by P starvation. 
Table 5. qRT-PCR expression of metabolic gene transcripts normalized with reference gene delta-CT $\left(\Delta \mathrm{C}_{\mathrm{T}}\right)$ are shown as fold changes $\left(\log _{2}[-\mathrm{P} /+\mathrm{P}]\right)$.

\begin{tabular}{ccccccc}
\hline \multirow{2}{*}{ Genes } & \multicolumn{3}{c}{ Fengqing } & \multicolumn{3}{c}{ Longjing-43 } \\
\cline { 2 - 7 } & Young Shoots & Leaves & Root & Young Shoots & Leaves & Root \\
\hline BCAT1 & $0.88^{* *}$ & $1.15^{*}$ & $0.86^{* *}$ & $0.88^{* *}$ & $0.85^{*}$ & $0.92^{* *}$ \\
TSA1 & $1.19^{*}$ & $1.50^{* *}$ & $1.12^{* * *}$ & $1.61^{* * *}$ & $0.85^{* * *}$ & $0.92^{* * *}$ \\
ADT1 & $1.55^{* * *}$ & $1.09^{*}$ & $0.87^{*}$ & $0.91^{* *}$ & $1.15^{* *}$ & $0.67^{\mathrm{NS}}$ \\
MS2 & $0.92^{* *}$ & $1.03^{\mathrm{NS}}$ & $0.86^{*}$ & $1.67^{* * *}$ & $0.98^{\mathrm{NS}}$ & $0.99^{\mathrm{NS}}$ \\
NPL3 & $0.98^{*}$ & $0.93^{\mathrm{NS}}$ & $0.85^{* *}$ & $0.58^{* * *}$ & $1.05^{*}$ & $0.92^{*}$ \\
GLT1 & $0.88^{*}$ & $1.56^{* *}$ & $0.63^{* *}$ & $0.71^{* *}$ & $0.90^{*}$ & $1.01^{\mathrm{NS}}$ \\
ACS & $0.85^{* *}$ & $1.34^{* *}$ & $0.87^{* *}$ & $1.62^{* * *}$ & $0.92^{*}$ & $1.19^{* * *}$ \\
P4H & $0.96^{*}$ & $1.30^{* *}$ & $1.01^{\mathrm{NS}}$ & $1.62^{* *}$ & $0.91^{*}$ & $1.27^{*}$ \\
ANR & $1.02^{\mathrm{NS}}$ & $2.08^{\mathrm{NS}}$ & $1.06^{*}$ & $1.16^{\mathrm{NS}}$ & $0.63^{* *}$ & $0.56^{* * *}$ \\
LDOX & $0.96^{\mathrm{NS}}$ & $0.95^{*}$ & $1.10^{\mathrm{NS}}$ & $1.74^{* *}$ & $0.62^{* * *}$ & $1.02^{\mathrm{NS}}$ \\
UGT75L12 & $0.83^{* *}$ & $1.04^{*}$ & $0.80^{* *}$ & $2.17^{* * *}$ & $0.89^{* *}$ & $1.17^{*}$ \\
UGT78D1 & $0.92^{*}$ & $1.46^{*}$ & $0.96^{*}$ & $1.19^{*}$ & $0.92^{*}$ & $0.97^{\mathrm{NS}}$ \\
UGT78D2 & $0.84^{* * *}$ & $1.17^{*}$ & $0.70^{* * *}$ & $1.70^{* * *}$ & $0.86^{* *}$ & $0.81^{*}$ \\
\hline
\end{tabular}

NS, ${ }^{* * * * *}$ and $*$ indicate not significant or significance at $0.001,0.01$, and 0.05 levels between $P$ treatments by $t$-test, respectively.

\subsection{Correlation and Pathway Impact Analysis of Metabolites and Gene Expression with High-Fold} Response Ratios

In the map of Fengqing (Figure 5A), we found genes were distinctly clustered into first (NPL3, GLT1 and UGT57L12), second (UGT78D1, ACS, LDOX, P4H and MS2) and third (ANR, ADT1, BCAT1, TSA1 and UGT78D2) major hierarchal groups to show their similar expression of correlations with abundance of metabolites. The significant results from first group indicate that NPL3 positively correlated with paratocarpin A while negatively with luteolin 7-O glucoside and fructose. Similarly, GLT1 shared strong and negative correlation with myo-inositol. Most of the gene (P4H,MS2 and ACS) in the second group were strongly correlated with catechins. The result showed that epicatechin positively and epiafzelechin-epicatechin 3,3'-digallate negatively correlated with those genes. Glycine negatively correlated with P4H, MS2 and LDOX. Most of the metabolites in the third group correlated with ADT1, either positively for Thr and Ala or negatively for Phe, delphinidin, and quercetin-3,4'-diglucoside. Likewise, in Longjing-43 (Figure 5B), MS2 and ANR were distinctly clustered to an analogous pattern of correlation expression with metabolites. MS2 strongly correlated with luteolin 7-O glucoside. BCAT1, UGT57L12, ACS, UGT78D1, TSA1 and UGT78D2 were clustered into another group BCAT1 strongly correlated with most of the flavonoid compounds, either positively with rutin, paratocarpin A, cyanidin, delphinidin, quercetin-3,4'-diglucoside or negatively with Spinacetin 3-gentioboside and Tectorigenin 7-sulfate. ACS, UGT57L12 and UGT78D1 share the parallel negative correlation with Gln, glycine and D-xylose. Interestingly, TSA1 share only the negative correlation with myo-inositol. 
A

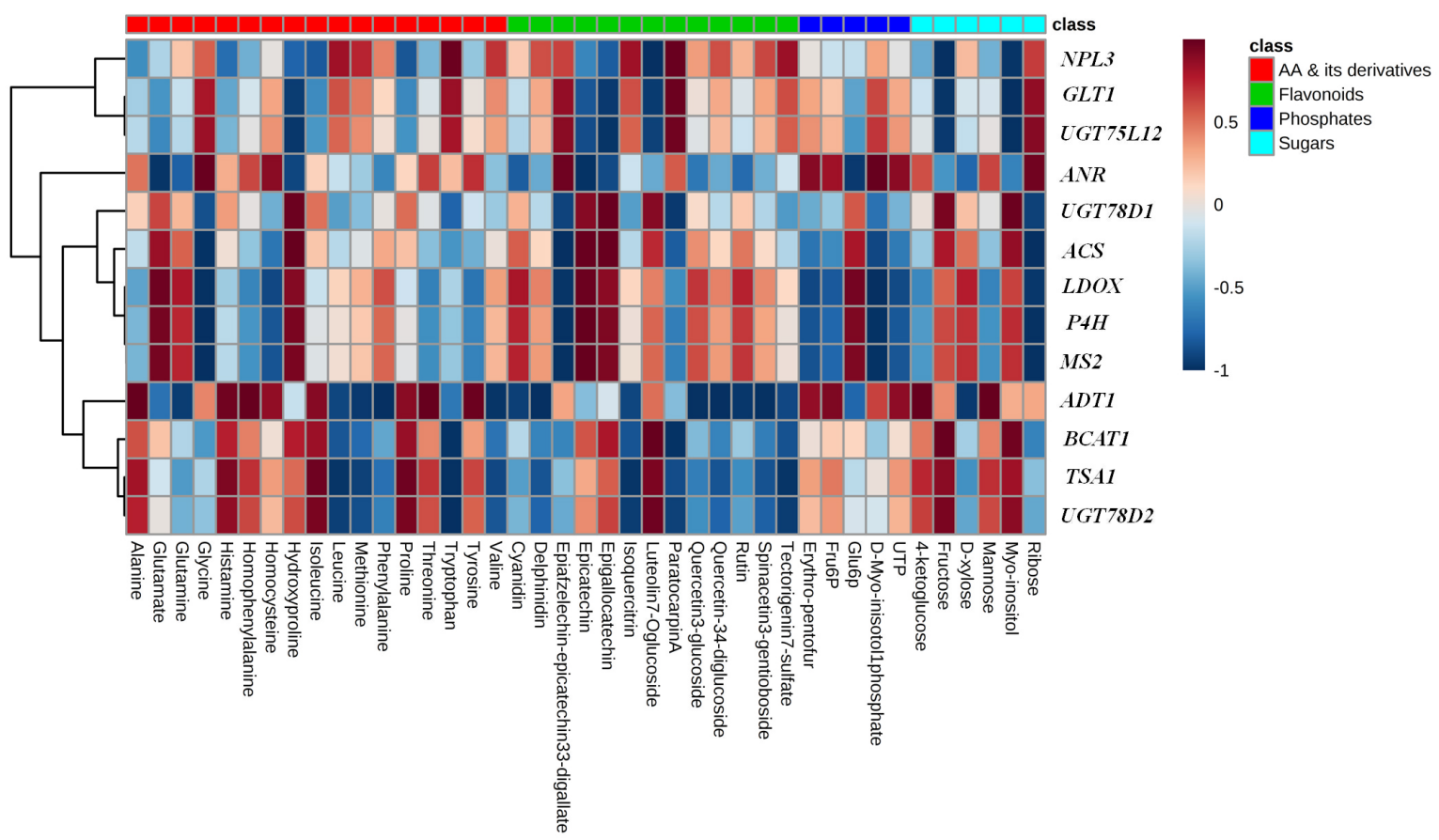

B

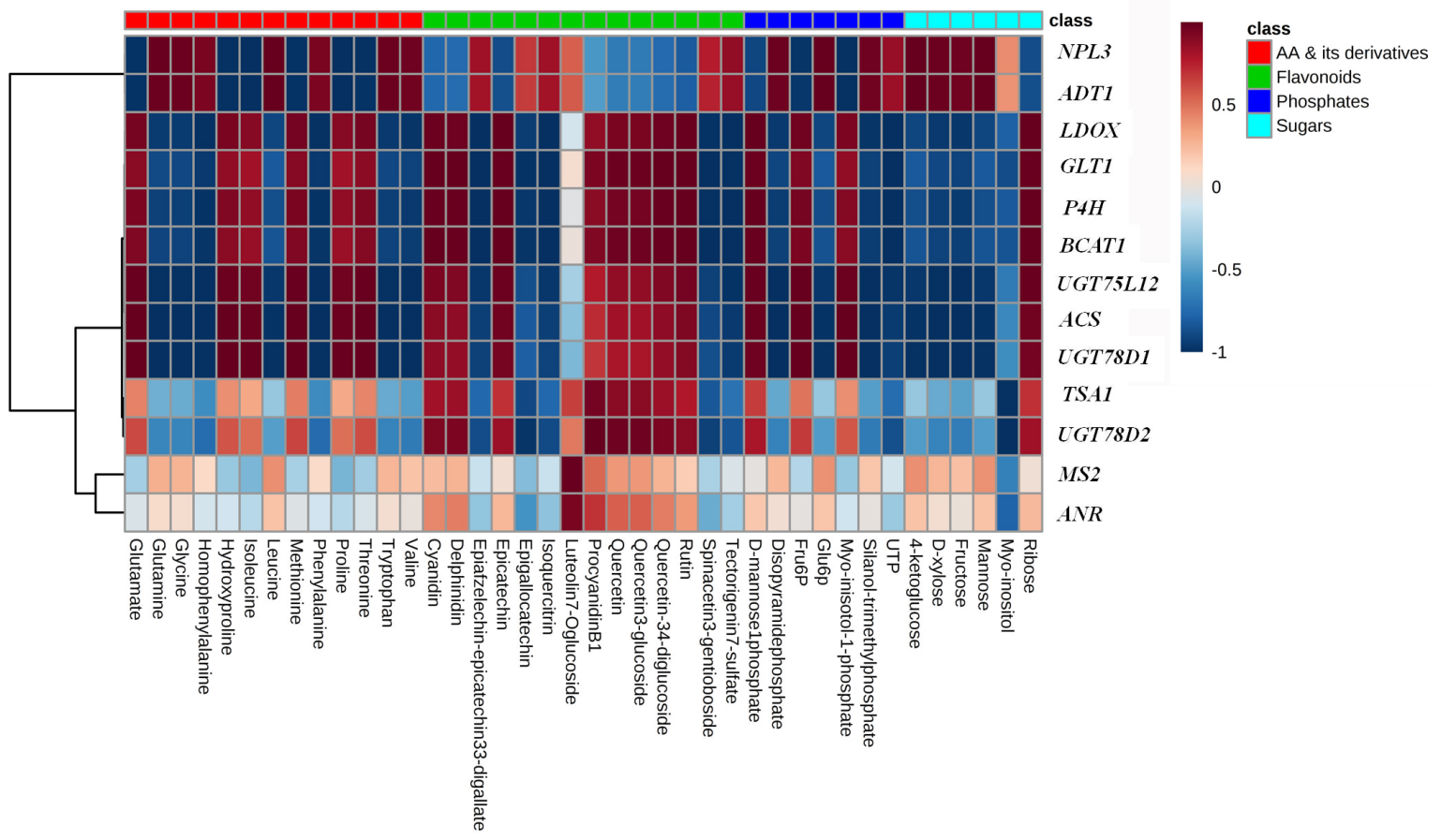

Figure 5. Heat map of correlations between fold change $\left(\log _{2}[-\mathrm{P} /+\mathrm{P}]\right)$ of selected significantly changed ( $p<0.05, t$-test) metabolites and metabolic genes in young shoots. Red and blue colors indicate positive and negative coefficients and their scales indicate values of Fengqing (A) and Longjing-43 (B). 


\section{Discussion}

Exposure of plants to Pi starvation has effects at morphological [27], physiological [28], biochemical [4,29-32] and molecular [33,34] levels. In this study, Longing-43 was found more sensitive to Pi-depletion than Fengqing cultivars showing different efficiency of cultivars to P use (Table 1). Starvation of $\mathrm{P}$ supply led to significantly decreased $\mathrm{P}$ concentrations in tea plants, inducing strong root morphological changes (Tables 1 and 2). Root volume and surface area were strongly reduced whereas the lateral root length was significantly extended. This observation is in line with previous findings, as recently reviewed, that elongation of lateral root increased by P limitation [35]. However, we observed a decreased number of root tips in contrast to enhanced lateral root formation, which might be explained by the fact that response of root morphological properties is variable upon plant species and even cultivars [36]. This explanation is supported by recent findings that change in total root length, number of root tips and root surface varied significantly among barley (Hordeum vulgare), canola (Brassica napus), and potato (Solanum tuberosum) [37]. In previous studies, sugar (particularly sucrose) has been proposed to act as a trigger for the transcription of Pi-stress induction and Glc as transcription signal call for gene involved in cell division and respiration [38,39]. Such an effect also has been attributed to remobilization of sugars from leaves to root, causing changes in root growth parameters by P starvation. Thus, the positive changes of sugar metabolites (Supplementary Table S1; tremendously increased Fru and Glc in leaves, and Glc, D-xylose and gluconate in root) might have contributed to the changes in root parameters (Table 2).

There are several metabolomics studies and some of them integrated with metabolic genes on the response to Pi-stress $[10,11,14,40]$. Our analysis revealed that transcription factors SPX2 had close relation with effect on the distribution of $\mathrm{Pi}$ in different plant organs that ultimately influenced on metabolic pathways. Several studies have shown that leaf and root could act as a source to provide metabolites to young shoots as sinks. For example, theanine synthesis occurs in roots and is transported above-ground and mainly young shoots [41,42]. Mature leaves are the source of carbohydrate, providing metabolites to young shoots and the metabolism of lipids [43]. We observed largely variable response of metabolites to P starvation in different organs; i.e., leaves, roots, and young shoots. Otherwise, $\mathrm{P}$ is highly mobile within plants and preferentially transported to the growth center young shoots, which is a tolerance mechanism of tea plants to low P supply [26]. Therefore, we conducted studies not only in young shoots but also in leaf and root.

One of the generally uniform findings under P starvation is the depletion of phosphorylated metabolites $[10,14]$. This was confirmed by the present work that D-mannose-1-phosphate in leaves immensely decreased (Figure 1 and Table S1). Ding et al. [24] also reported reduced contents of phosphorylated metabolites in P-deficient tea leaves. On the other hand, it was frequently observed that carbohydrates and amino acids accumulated under $P$ starvation $[10,11,14,40]$. This observation is in accordance with the present result showing that carbohydrates (Fru and Glc) in leaves and some amino acids (Thr, hydroxyproline and Met) in leaves and (Phe, Ala, Trp and Tyr) in root accumulated by extremely high folds in P-starved tea plants (Table S1). Elevated carbohydrates in source leaves might be a result of weak sink requirement and use imposed by stunned growth of young shoots or/and Pi saving mechanism in which the retention of sugars in the vacuole sequesters them from phosphorylation reactions [6]. Our data, however, contradicts recent observations that Fru and Glc decreased in P-stressed tea leaves [24]. We observed opposite changes of Pyr and Ala in leaves and root (Table S1). The ratio of Pyr/Ala has been taken as an indicator of metabolic flux of Pyr to Ala synthesis or to Krebs cycle [44]. In this context, the ratio of Pyr/Ala significantly decreased in root but increased in leaves, suggesting different adjustment of $\mathrm{N}$ and $\mathrm{C}$ metabolism in leaves and root in response to P deficiency (Table S1). The accumulation of hydroxyproline under P starvation was accompanied by upregulated expression of $\mathrm{P} 4 \mathrm{H}$. The formation of 4-hydroxyproline from Pro is involved in plant responses to abiotic stress (hypoxic, anoxic, waterlogging and wounding) [45]. Our work suggests that hydroxylation of Pro by $\mathrm{P} 4 \mathrm{H}$ might also be linked to the response to $\mathrm{P}$ deficiency. One surprising finding was that EA significantly depleted by 4.6-27.0-fold in leaves under P starvation 
(Table S1). A recent work demonstrated phosphoethanolamine hydrolysis catalyzed by AtPECP1, resulting increased EA during Pi starvation [46]. The reason for such difference is unknown and therefore requires further work. To our surprise, there was no significant change of organic acids such as citrate, malate, and oxalate in root, which were frequently reported to be exudated to rhizosphere to mine soil phosphate [25]. However, other organic acids, i.e., quinic acid and shikimic acid in root were significantly elevated. Shikimate is the precursor for Phe biosynthesis and thereby downstream metabolites of flavonoids. Increased shikimate in the root of P deficiency is consistent with elevated accumulation of flavonoids (Figure 2).

Several flavonoids accumulated in leaves (Delphinidin, cyanidin, procyanidin B1) and roots [procyanidin B1, epiafzelechin-epicatechin 3,3'-digallate, (-)-epigallocatechin 3,3'-di-gallate, malvidin and (-)-Epiafzelechin 3-gallate] of a tea plant exposed to P limitation (Figure 2 and Table S2). This agrees with previous findings [10]. Consistent with these changes, the expression of genes ANR and LDOX related to the biosynthesis pathway of these metabolites was largely upregulated. On the other hand, flavonoid glycosides in leaves (luteolin-7-O-glucoside, rutin, Isoquercitrin and licorice glycoside A) and roots (Diosmetin 7-O-beta-D-glucuronopyranoside, tricin 7-glucuronide and prunin 6"-p-coumarate) were also remarkably elevated by $\mathrm{P}$ starvation, which is in accordance with enhanced expression of UGTs (UGT78D1, UGT78D2 and UGT57L12). Flavonoids in plants are glycosylated to modified stability, solubility, localization, and thereby the biological properties. A compromised 3-O-glycosylation led to the repression of flavanol biosynthesis along with the inhibition of flavanol biosynthetic genes [47]. The 3-O-glycosylation of flavanols (kaempferol, quercetin) is catalyzed by the UGT78D family, with UGT78D1 using UDP-rhamnose and UGT78D2 using UDP-glucose [48]. The recently identified gene-encoding flavonoid 7-O-glycosyltransferase (CsUGT75L12) in tea plant displays glycosyltransferase activity on the 7-OH position of multiple phenolic compounds [49]. In the present work, we observed low levels of m-trigallic acid and 2,4-dihydroxybenzoic acid, a finding in agreement with previous ones of decreased benzoids in P-starved Arabidopsis [10]. Furthermore, chalcone also decreased while most flavonoids increased in young shoots under $P$ deficiency. Competition for substrates between upstream and downstream branches of the phenylpropanoid pathway in tea plants has been suggested [50].

In young shoots, the highly accumulated carbohydrates were D-xylose and ribose, mannose and 4-ketoglucose in strongly contrast with highly increased Fru and Glc in leaves (Figure 1 and Table S1). Furthermore, D-myo-inositol 1 phosphate remarkably increased whereas myo-inositol decreased. Inositol and its derivatives are crucial for development and signaling in plants, either as metabolic mediators or participating in various signaling pathways in response to stress, hormones, and nutrients, by transcriptional regulation of the stimuli-responsive genes [51]. Declining myo-inositol biosynthesis in leaves led to programmed cell death in Arabidopsis mips1 mutants [52,53]. On the other hand, we observed increased phosphorylated metabolites (D-myo-inositol 1 phosphate and D-erythro-Pentofuranose phosphate) in young shoots in contrast to those in leaves and roots (Figure 1 and Table S1). This might be explained by the fact that these metabolites play important roles and are therefore essentially maintained at higher levels for new growth under P limitation. Both metabolomics and targeted analyses showed remarkably lower level of Gly in young shoots of both cultivars exposed to $-\mathrm{P}$ treatment (Table S1 and Table 3). Though Ser contents responded different between the two cultivars, the ratio Gly/Ser was greatly decreased by $-\mathrm{P}$ treatment (5.0, 3.9 at $\mathrm{P}$ sufficiency and $1.8,0.6$ at $\mathrm{P}$ deficiency for Fengqing and Longing-43, respectively) (Table 3). The ratio Gly/Ser is a good marker of photorespiration and correlates well with the flux of $C$ through the photorespiratory pathway, regardless of the absolute amounts of each amino acid [54]. Significantly decreased Asp concentrations in both cultivars further supported the conclusion that photorespiration in young shoots was repressed by P deficiency [55]. This finding, however, is in contrast with increased Gly/Ser ratio after short-term P deficiency and activated photorespiration by $P$ stress [6,56]. Increase in amino acid Pro in our study corresponds to previous one in the tea plant [23], indicating that P stress accelerates Pro accumulation. A recent work in Arabidopsis showed the link of Pro metabolism and P nutrition and revealed that the activated Pro biosynthesis is regulated by cross talk between ABA signaling and 
regulation of phosphate homeostasis through PHR1 [57]. Therefore, depleted myo-inositol, abnormal Pro accumulation and inactivated photorespiration likely mean the strongly stunted growth of young shoots due to P limitation.

The quality of tea is dependent upon chemical components in young shoots. Therefore, the targeted metabolites in young shoots were further determined. Earlier investigation showed that P-deficient green tea displayed decreased concentrations of total free amino acid, total polyphenol and individual components Thea, Asp, Glu and ECG, EC, GCG and CG without affecting total catechins and EGCG [23]. The present result suggested, however, a more complicated response of these metabolites to $P$ stress, especially between the two cultivars. The uniformly changed metabolites within the two cultivars include amino acids Asp, Gly, Leu, Pro, Ile, and catechin. Other amino acids including the predominating Thea and others (Ser, Thr, Glu, Val, Met, Phe), and some catechins (EGC and ECG) displayed opposite changes in response to P stress between the two cultivars.

\section{Materials and Methods}

\subsection{Plant Cultivation, $P$ Treatment and Sampling}

The six-months-old seedlings of the cultivar Longjing-43 (12.0 $\pm 0.4 \mathrm{~g})$ (Tea Research Institute, Chinese Academy of Agricultural Sciences (TRI CAAS), Hangzhou, Zhejiang, China) propagated from rooted-cuttings and Fengqing $(5.9 \pm 0.3 \mathrm{~g})$ (Tea Research Institute, Fengqing, Yunnan, China) germinated from seeds were cultivated in pots filled with $4 \mathrm{~L}$ nutrient solutions. The basic composition of nutrient solutions were macronutrients $(\mathrm{mM})\left(\mathrm{NH}_{4}\right)_{2} \mathrm{SO}_{4}(2), \mathrm{Ca}\left(\mathrm{NO}_{3}\right)_{2}(1), \mathrm{K}_{2} \mathrm{SO}_{4}(1), \mathrm{MgSO}_{4}(0.4)$, $\mathrm{CaCl}_{2}(0.8)$ and micronutrients $(\mu \mathrm{M}) \operatorname{FeEDTA}(0.08), \mathrm{H}_{3} \mathrm{BO}_{3}(10), \mathrm{MnSO}_{4}(1.5), \mathrm{ZnSO}_{4}, \mathrm{CuSO}_{4}(0.2)$ and $\left(\mathrm{NH}_{4}\right)_{6} \mathrm{Mo}_{7} \mathrm{O}_{2} 4(0.5)$ (Nutrition Chemicals; Shanghai Lingfeng Chemical Reagent Co. Ltd., Shanghai, China). The level of $\mathrm{P}$ was $0.1 \mathrm{mM}$ solution supplied as $\mathrm{KH}_{2} \mathrm{PO}_{4}$, whereas rest of the seedlings grown without P. The $\mathrm{pH}$ ( $\mathrm{pH}$ meter; Orion A215, Thermo Fisher Scientific Inc., Waltham, MA, USA) of nutrient solutions was daily adjusted to 5.0 by adding $0.1 \mathrm{M} \mathrm{H}_{2} \mathrm{SO}_{4}$ or $\mathrm{NaOH}$ solution. There were 8 pot replications or 32 plants for each cultivar (cv.). The plants were cultivated for three months in a greenhouse under natural light 25,643 $\pm 3987 \mathrm{LUX}$ (LiCor LI-250A connected to quantum sensor (LI-190SA), Lincoln, NE, USA) at room temperature $\left(25 \pm 2{ }^{\circ} \mathrm{C}\right)$. During this period, young shoots were sampled 4-6 times after 90 days of exposition to $P$ treatments from the plants whenever they reached the desired developmental stage for harvesting, which is the common standard for green and black tea. In addition, leaf and fibrous root were also sampled as they act as source provide metabolites to young shoots as sink. All plant samples including young shoots, leaves and roots were quickly frozen in liquid nitrogen and stored in an ultra-low temperature refrigerator at $-80^{\circ} \mathrm{C}$ for further analysis.

\subsection{Measurements of Root Growth Parameters and Concentrations of Pi}

A weighted batch of fresh fibrous root sample was randomly selected from the collected samples and was scanned with an Epson V700 scanner (B11B178011, EPSON, Long Beach, CA, USA) in 600 dpi. Parameters of root volume $\left(\mathrm{cm}^{3}\right)$, surface area $\left(\mathrm{cm}^{2}\right)$, total number of tips, length $(\mathrm{cm})$ and thickness $(\mathrm{cm})$ were calculated from the images using Root Graph phenotyping program, by setting the threshold scalar at 0.6 to remove noise [58]. Pi concentration in freeze-dried plant samples was measured by ICP-AES (iCAP6300DUO, Thermo Fisher Scientific Inc., Waltham, MA, USA) following digestion with concentrated $\mathrm{HNO}_{3}$ and $\mathrm{HClO}_{4}$ [59].

\subsection{GC $\times$ GC-TOF/MS Analysis for Primary Metabolites}

Freeze-dried young shoots, leaves, and root samples $(100.00 \mathrm{mg})$ with four biological replicates each was added to $1000 \mu \mathrm{L}$ of methanol-chloroform (3:1, v/v) solvent (Sigma-Aldrich Co., St. Louis, $\mathrm{MO}, \mathrm{USA}) .10 \mu \mathrm{L}$ L-2-chlorophenylalanine $(0.3 \mathrm{mg} / \mathrm{mL}$ in water) was mixed with the resultant extract. The samples were centrifuged for $10 \mathrm{~min}$ at $12,000 \mathrm{rpm}$ at $-4{ }^{\circ} \mathrm{C}$; the supernatant $(400 \mu \mathrm{L})$ was dried in a vacuum concentrator without heating, and later frozen in liquid nitrogen. $80 \mu \mathrm{L}$ methoxyamine 
( $15 \mathrm{mg} / \mathrm{mL}$ in pyridine) was added to the dried sample and vortexed for $1 \mathrm{~min}$. Methoxymation was performed at $37^{\circ} \mathrm{C}$ for $120 \mathrm{~min}$ in drying oven. Subsequently, the sample were trimethylsilylated at $70{ }^{\circ} \mathrm{C}$ for 90 min by adding $80 \mu \mathrm{L}$ BSTFA (containing $1 \%$ TMCS) to the solution.

The machine consisted of an Agilent GC 6890N gas chromatograph, the high-speed TOF mass spectrometer detector (Pegasus HT, Leco Co., St. Joseph, MI, USA). First dimensional, DB-5 MS capillary column (30 $\mathrm{m} \times 250 \mu \mathrm{m}$ i.d., $0.25 \mu \mathrm{m}$ film thickness; JandW Scientific, Folsom, CA, USA) and second dimension column DB-17H $2.5 \mathrm{~m} \times 0.1 \mathrm{~mm}$ I.D., $0.1 \mu \mathrm{m}$ film thickness. The rest of the machine conditions were according to the previously described in method by Liu et al. [60].

Data files from GC $\times$ GC-TOF/MS were processed in Leco software (Leco Co., St. Joseph, MI, USA) and were deconvoluted using System. The corresponding peaks of chromatogram were compared to the NIST mass spectral database (National Institute of Standards and Technology, FairCom Co., Gaithersburg, MD, USA) to identify metabolites.

\subsection{UPLC-Q-TOF/MS Analysis for Secondary Metabolites}

Samples stored at $-80{ }^{\circ} \mathrm{C}$ in liquid nitrogen were finely milled. The milled four biological replicated samples were weighed to exactly $0.1 \mathrm{~g}$ with the help of ice crucible in Eppendorf tube. The metabolites in weighed samples were extracted using $80 \%$ methanol and $1 \%$ formic acid (Sigma-Aldrich Co., St. Louis, MO, USA) as indicated by [50,61]. The extracted $2 \mathrm{~mL}$ solvent were bathed ultrasonically for $10 \mathrm{~min}$, while turning the hands both up and down twice in 5 min interval, and after centrifuged at 12,000 r/min. Extracts were filtered through a $0.22 \mu \mathrm{m}$ PTFE filters before injection into 1 dram glass vessel for metabolomics analysis.

Metabolomics analysis was performed on an ultra-performance liquid chromatography (ACQUITY UPLC, Waters Corp., Milford, MA, USA), which was equipped with an Acquity HSS T 3 columns (1.8 mm, $100 \mathrm{~mm} 62.1 \mathrm{~mm}$, Waters Corp., Milford, MA, USA) and connected to a quadrupole-time of flight mass spectrometer (Xevo G2-XS QTOF, Waters Corp., Milford, MA, USA). Mobile solutions and rest of the machine conditions were adjusted as previously referred to in method [50].

Raw chromatographic data acquired from the UPLC-Q-TOF/MS analysis were exported into a comma delimited file ( ${ }^{*}$.csv) by TransOmics (Waters Corp., Milford, MA, USA). Metabolite peaks were annotated from the accurate mass measurements using online metabolite databases. Peaks were identified based on (i) actual mass (AM), retention time (RT) and standard; (ii) AM and RT; (iii) AM and isotopic distribution (ID) as prescribed by [50]. The identified peaks can be further classified into identified compounds (i and ii) and putatively annotated compounds (iii) according to the proposed minimum reporting standards for chemical analysis [62].

\subsection{Extraction and Determination of Targeted Catechin and Amino Acid by High Performance Liquid Chromatography (HPLC) Analysis}

Samples were assigned and extracted same as UPLC-Q-TOF/MS for catechin determination. For free amino acid analysis samples were derivatized as the instruction provided by waters AccQ.Tag chemistry package. HPLC analysis was carried out using an e2695 connecting 2998 photodiode array detector system (Waters) injected with $10 \mu \mathrm{L}$ and $25 \mu \mathrm{L}$ of sample solutions for catechin and free amino acid respectively. For catechins distilled water with $2 \%$ formic acid was used as mobile phase A. Mobile phase B consisted of HPLC solvent ACN (Sigma-Aldrich Co., St. Louis, MO, USA). The samples were eluted at column temperature $40 \pm 1{ }^{\circ} \mathrm{C}$ at a flow rate of $1 \mathrm{~mL} / \mathrm{min}$ and monitored at $278 \mathrm{~nm}$. Similarly, for amino acid AccQ.Tag eluent from waters was used as mobile phase A. Mobile phase B was ACN and column temperature was set at $37 \pm 2{ }^{\circ} \mathrm{C}$. Rests of the procedure was followed as prescribed in AccQ. Tag chemistry package instruction manual. Peaks of catechins were identified by comparing the retention time of the sample to those of authentic standards and amino acids were as prescribed in the manual. 


\subsection{Quantitative Real-Time Polymerase Chain Reaction (QRT-PCR) Expression Analysis}

Young shoots and leaves from Pi-starved $(-\mathrm{P})$ and Pi-sufficient plants $(+\mathrm{P})$ of two cultivars were used for RNA extraction. RNA was extracted from fresh young shoots, leaves of P-starved and P-sufficient plants each in three biological replicates using the RNeasy Plant Mini kit following the protocol provided by the producer [63] and from root following prescription by Tao et al. [64].

cDNA synthesis using PrimeScript RT Reagent Kit according to manufacturer instructions was carried out. cDNA quality from young shoots, leaves, and root from $+\mathrm{P}$ and $-\mathrm{P}$ were tested. The transcript of three $\mathrm{Pi}$ transporter genes and expression of 13 phosphate starvation selected metabolic genes was quantified using a 7500 HT Real-Time PCR system (Applied Biosystems, Foster, CA, USA). The three-transcription factor gene (PHR1, PHO1 and SPX2) and 13 metabolic genes were analyzed as fold change after normalizing $\mathrm{C}_{\mathrm{T}}$ with the reference gene GAPDH [65]. In addition, three-transcription factor use linear regression with respect to Pi content change in different plant organs to formulate the dependent factor, whereas the rest of the genes were shown as fold difference in expression. The primer sequences of the gene used for qRT-PCR are shown in Tables S3-S5.

To integrate primary and secondary metabolites changes with gene expression, the fold changes of primary and secondary metabolites were checked with the corresponding expression of pathway metabolic genes. qRT-PCR expression profiling involving 13 genes transcript were performed in leaves, root, and young shoots of Fengqing and Longjing-43 cultivar. The gene was selected from in between the pathway metabolites that were derived as VIP from SIMCA software and were further referenced from Kyoto Encyclopedia of Genes and Genomes (KEGG) database (http:/ /www.genome.jp/kegg/) and Plant Metabolic Network (PMN) (www.plantcyc.org).

\subsection{Data Analysis, Visualization, and Cross Verification}

Pi content in root, leaves and, young shoots and targeted metabolites amino acid and catechins content in young shoots measurements were entered into MS Excel 2013 (Microsoft Co., Redmond, WA, USA), and later an analysis of variance test and Pearson's correlation on selected untargeted quality-related metabolites was performed at $95 \%$ confidence interval (CI) or 0.05 level of significance in SPSS (Version 22, IBM, Chicago, IL, USA.) software. Figures were prepared using Power Point 2013 (Microsoft Co., Redmond, WA, USA), HeatMapper Plus Tool (http://bar.untoronto.ca) or Cytoscape 3.02 (http:/ / www.cytoscape.org/) and graphs using R 3.2.3. SIMCA 13.0.3 (Umetrics, MKS Instruments Inc., Umeå, Sweden) software was used to apply umetrics model to sort GC $\times$ GC-TOF/MS and UPLC-Q-TOF/MS data.

The UPLC-Q-TOF/MS and GC $\times$ GC-TOF/MS data were exported to SIMCA 13.0.3 software for multivariate data analyses. An unsupervised principal component analysis (PCA) was performed for the data obtained from GC $\times$ GC-TOF/MS and UPLC-Q-TOF/MS for a general overview of the variance of metabolites in the treatments using SIMCA-P (version 13.0, Umetrics, MKS Instruments Inc., Umeå, Sweden). The supervised orthogonal projection to latent structure discriminant analysis (OPLS-DA) was carried out to obtain cluster information on differences in the treatment. The VIP values of all the data from the double cross and 7-fold cross validated OPLS model, was taken as coefficients for metabolite selection for GC $\times$ GC-TOF/MS and UPLC-Q-TOF/MS, respectively. Those variables with VIP $>1$ were selected and a student $t$-test was performed on a different group of plant organs for treated metabolites, to test for significance of the selected group of metabolites, as well as on each metabolite. Response ratio $(-\mathrm{P} /+\mathrm{P})$ of significantly changed parameters of root growth and $\mathrm{P}$ concentrations and metabolites was $\log _{2}$ transformed and referred to as 'fold change' to show the effects of $-\mathrm{P}$ treatment. The heatmap of correlation matrices was built to show the correlation relation between metabolites and metabolic gene in young shoots. 


\section{Conclusions}

In summary, P deficits increase in carbohydrates (fructose and glucose) and amino acid metabolites such as threonine and methionine cause weak sink requirement with low production rate. The different amount of higher and upregulated change response of $\mathrm{Pi}$ in roots and interlinkage of this change with SPX2 in other organs further explains Longing-43 is more sensitive to Pi-depletion than Fengqing cultivar. Some amino acid metabolites, such as phenylalanine, alanine, tryptophan, and tyrosine accumulated by extremely high fold in root during this occasion. The predominating theanine and other amino acids (serine, threonine, glutamate, valine, methionine, phenylalanine), and catechin (EGC, EGCG and CG) content explains two tea cultivars have a different metabolic response to Pi deficiency. The consistent changes in numbers of amino acids and flavonoids in biosynthetic pathway with expression profile of genes (ANR, LDOX and UGTs) revealed cultivars leading molecular regulatory network mechanisms behind $\mathrm{P}$ deficiency.

Supplementary Materials: The following are available online at http:/ / www.mdpi.com/1422-0067/19/11/3683/ s1, Figure S1: Supervised and Unsupervised OPLS-DA and Permutations test, with variables phosphate starvation $(-\mathrm{P})$ and phosphate sufficient $(+\mathrm{P})$ samples, Table S1: Fold changes $\left(\log _{2}[-\mathrm{P} /+\mathrm{P}]\right)$ and $t$-test of selected metabolites in tea plants in response to $P$ limitation measured by GC $\times$ GC-TOF/MS, Table S2: Fold changes $\left(\log _{2}[-\mathrm{P} /+\mathrm{P}]\right)$ and $t$-test of selected metabolites in tea plants in response to P limitation measured by UPLC-Q-TOF/MS. Table S3: Transcription factor primer sequences for Fengqing ( $v$. assamica) and Longjing-43 ( $c v$. sinensis) for qRT-PCR analysis., Table S4: Primer sequences for the gene transcripts of Fengqing (cv. sinensis) cultivar of selected pathways for qRT-PCR analysis., Table S5: Primer sequences for the gene transcripts of Longjing-43 (cv. assamica) cultivar of selected pathways for qRT-PCR analysis.

Author Contributions: Conceptualization, J.R. and S.K.C.; Methodology, M.L. and Q.Z.; Validation, J.R. and Y.S.; Formal analysis, S.K.C.; Investigation, S.K.C.; Resources, Y.S.; Data curation, S.K.C.; Writing一original draft preparation, S.K.C.; Writing-review and editing, J.R., K.F. and M.L.; Visualization, Y.S. and M.L.; Supervision, J.R. and S.K.C.

Funding: This work was financially supported by the National Key Research and Development Program of China (2016YFD0200901), the Chinese Academy of Agricultural Sciences Innovation Project (CAAS-ASTIP-2017-TRICAAS), the Earmarked Fund for China Agriculture Research System Ministry of Agriculture of China (CARS 19) and the National Natural Science Foundation of China (No.31572199).

Acknowledgments: We will like to thank Shanghai Jiao Tong University for providing access to GC $\times$ GC-TOF/MS We also thank Zongmao Chen and Xinzhong Zhang for providing access to the UPLC-Q-TOF/MS and Liang Chen for providing access to qRT-PCR and assistance in using it.

Conflicts of Interest: The authors declare no conflict of interest.

\section{References}

1. Schachtman, D.P.; Reid, R.J.; Ayling, S.M. Phosphorus Uptake by Plants: From Soil to Cell. Plant Physiol. 1998, 116, 447-453. [CrossRef] [PubMed]

2. Poirier, Y.; Bucher, M. Phosphate transport and homeostasis in Arabidopsis. In The Arabidopsis Book; The American Society of Plant Biologists: Rockville, MD, USA, 2002; Volume 1, p. e0024. [CrossRef]

3. Brembu, T.; Muhlroth, A.; Alipanah, L.; Bones, A.M. The effects of phosphorus limitation on carbon metabolism in diatoms. Philos. Trans. R. Soc. Lond. B Biol. Sci. 2017, 372, 20160406. [CrossRef] [PubMed]

4. Lynch, J.P. Root phenes for enhanced soil exploration and phosphorus acquisition: Tools for future crops. Plant Physiol. 2011, 156, 1041-1049. [CrossRef] [PubMed]

5. Plaxton, W.C.; Tran, H.T. Metabolic adaptations of phosphate-starved plants. Plant Physiol. 2011, 156, 1006-1015. [CrossRef] [PubMed]

6. Alexova, R.; Nelson, C.J.; Millar, A.H. Temporal development of the barley leaf metabolic response to Pi limitation. Plant Cell Environ. 2017, 40, 645-657. [CrossRef] [PubMed]

7. Byrne, S.L.; Foito, A.; Hedley, P.E.; Morris, J.A.; Stewart, D.; Barth, S. Early response mechanisms of perennial ryegrass (Lolium perenne) to phosphorus deficiency. Ann. Bot. 2011, 107, 243-254. [CrossRef] [PubMed] 
8. Ganie, A.H.; Ahmad, A.; Pandey, R.; Aref, I.M.; Yousuf, P.Y.; Ahmad, S.; Iqbal, M. Metabolite Profiling of Low-P Tolerant and Low-P Sensitive Maize Genotypes under Phosphorus Starvation and Restoration Conditions. PLoS ONE 2015, 10, e0129520. [CrossRef] [PubMed]

9. Müller, J.; Godde, V.; Niehaus, K.; Zorb, C. Metabolic Adaptations of White Lupin Roots and Shoots under Phosphorus Deficiency. Front. Plant Sci. 2015, 6, 1014. [CrossRef] [PubMed]

10. Pant, B.D.; Pant, P.; Erban, A.; Huhman, D.; Kopka, J.; Scheible, W.R. Identification of primary and secondary metabolites with phosphorus status-dependent abundance in Arabidopsis, and of the transcription factor PHR1 as a major regulator of metabolic changes during phosphorus limitation. Plant Cell Environ. 2015, 38, 172-187. [CrossRef] [PubMed]

11. Huang, C.Y.; Roessner, U.; Eickmeier, I.; Genc, Y.; Callahan, D.L.; Shirley, N.; Langridge, P.; Bacic, A. Metabolite profiling reveals distinct changes in carbon and nitrogen metabolism in phosphate-deficient barley plants (Hordeum vulgare L.). Plant Cell Physiol. 2008, 49, 691-703. [CrossRef] [PubMed]

12. Morcuende, R.; Bari, R.; Gibon, Y.; Zheng, W.; Pant, B.D.; Blasing, O.; Usadel, B.; Czechowski, T.; Udvardi, M.K.; Stitt, M.; et al. Genome-wide reprogramming of metabolism and regulatory networks of Arabidopsis in response to phosphorus. Plant Cell Environ. 2007, 30, 85-112. [CrossRef] [PubMed]

13. Warren, C.R. How does P affect photosynthesis and metabolite profiles of Eucalyptus globulus? Tree Physiol. 2011, 31, 727-739. [CrossRef] [PubMed]

14. Müller, R.; Morant, M.; Jarmer, H.; Nilsson, L.; Nielsen, T.H. Genome-wide analysis of the Arabidopsis leaf transcriptome reveals interaction of phosphate and sugar metabolism. Plant Physiol. 2007, 143, 156-171. [CrossRef] [PubMed]

15. Misson, J.; Raghothama, K.G.; Jain, A.; Jouhet, J.; Block, M.A.; Bligny, R.; Ortet, P.; Creff, A.; Somerville, S.; Rolland, N.; et al. A genome-wide transcriptional analysis using Arabidopsis thaliana Affymetrix gene chips determined plant responses to phosphate deprivation. Proc. Natl. Acad. Sci. USA 2005, 102, 11934-11939. [CrossRef] [PubMed]

16. Arpat, A.B.; Magliano, P.; Wege, S.; Rouached, H.; Stefanovic, A.; Poirier, Y. Functional expression of PHO1 to the Golgi and trans-Golgi network and its role in export of inorganic phosphate. Plant J. 2012, 71, 479-491. [CrossRef] [PubMed]

17. Duan, K.; Yi, K.; Dang, L.; Huang, H.; Wu, W.; Wu, P. Characterization of a sub-family of Arabidopsis genes with the SPX domain reveals their diverse functions in plant tolerance to phosphorus starvation. Plant J. 2008, 54, 965-975. [CrossRef] [PubMed]

18. Wang, Z.; Ruan, W.; Shi, J.; Zhang, L.; Xiang, D.; Yang, C.; Li, C.; Wu, Z.; Liu, Y.; Yu, Y.; et al. Rice SPX1 and SPX2 inhibit phosphate starvation responses through interacting with PHR2 in a phosphate-dependent manner. Proc. Natl. Acad. Sci. USA 2014, 111, 14953-14958. [CrossRef] [PubMed]

19. Hammond, J.P.; White, P.J. Sugar signalling in root responses to low P availability. Plant Physiol. 2011, 156, 1033-1040. [CrossRef] [PubMed]

20. Wu, P.; Ma, L.; Hou, X.; Wang, M.; Wu, Y.; Liu, F.; Deng, X.W. Phosphate starvation triggers distinct alterations of genome expression in Arabidopsis roots and leaves. Plant Physiol. 2003, 132, 1260-1271. [CrossRef] [PubMed]

21. Li, C.F.; Zhu, Y.; Yu, Y.; Zhao, Q.Y.; Wang, S.J.; Wang, X.C.; Yao, M.Z.; Luo, D.; Li, X.; Chen, L.; et al. Global transcriptome and gene regulation network for secondary metabolite biosynthesis of tea plant (Camellia sinensis). BMC Genom. 2015, 16, 560. [CrossRef] [PubMed]

22. Lin, Z.H.; Chen, L.S.; Chen, R.B.; Zhang, F.Z.; Jiang, H.X.; Tang, N. CO2 assimilation, ribulose-1,5-bisphosphate carboxylase/oxygenase, carbohydrates and photosynthetic electron transport probed by the JIP-test, of tea leaves in response to phosphorus supply. BMC Plant Biol. 2009, 9, 43. [CrossRef] [PubMed]

23. Lin, Z.H.; Qi, Y.P.; Chen, R.B.; Zhang, F.Z.; Chen, L.S. Effects of phosphorus supply on the quality of green tea. Food Chem. 2012, 130, 908-914. [CrossRef]

24. Ding, Z.; Jia, S.; Wang, Y.; Xiao, J.; Zhang, Y. Phosphate stresses affect ionome and metabolome in tea plants. Plant Physiol. Biochem. 2017, 120, 30-39. [CrossRef] [PubMed] 
25. Lin, Z.H.; Chen, L.S.; Chen, R.B.; Zhang, F.Z.; Jiang, H.X.; Tang, N.; Smith, B.R. Root release and metabolism of organic acids in tea plants in response to phosphorus supply. J. Plant Physiol. 2011, 168, 644-652. [CrossRef] [PubMed]

26. Salehi, S.; Hajiboland, R. A high internal phosphorus use efficiency in tea (Camellia sinensis L.) plants. Asian J. Plant Sci. 2008, 7, 30-36. [CrossRef]

27. Cheng, L.; Tang, X.; Vance, C.P.; White, P.J.; Zhang, F.; Shen, J. Interactions between light intensity and phosphorus nutrition affect the phosphate-mining capacity of white lupin (Lupinus albus L.). J. Exp. Bot. 2014, 65, 2995-3003. [CrossRef] [PubMed]

28. Stewart, A.; Chapman, W.; Jenkins, G.; Graham, I.; Martin, T.; Crozier, A. The effect of nitrogen and phosphorus deficiency on flavonol accumulation in plant tissues. Plant Cell Environ. 2001, 24,1189-1197. [CrossRef]

29. Bates, T.R.; Lynch, J.P. Root hairs confer a competitive advantage under low phosphorus availability. Plant Soil 2001, 236, 243-250. [CrossRef]

30. Lambers, H.; Finnegan, P.M.; Laliberté, E; Etienne; Pearse, S.J.; Ryan, M.H.; Shane, M.W.; Veneklaas, E.J. Phosphorus Nutrition of Proteaceae in Severely Phosphorus-Impoverished Soils: Are There Lessons To Be Learned for Future Crops? Plant Physiol. 2011, 156, 1058-1066. [CrossRef] [PubMed]

31. Raghothama, K.G.; Karthikeyan, A.S. Phosphate acquisition. Plant Soil 2005, 274, 37. [CrossRef]

32. Williamson, L.C.; Ribrioux, S.P.; Fitter, A.H.; Leyser, H.M. Phosphate availability regulates root system architecture in Arabidopsis. Plant Physiol. 2001, 126, 875-882. [CrossRef] [PubMed]

33. Puga, M.I.; Mateos, I.; Charukesi, R.; Wang, Z.; Franco-Zorrilla, J.M.; de Lorenzo, L.; Irigoyen, M.L.; Masiero, S.; Bustos, R.; Rodriguez, J.; et al. SPX1 is a phosphate-dependent inhibitor of Phosphate Starvation Response 1 in Arabidopsis. Proc. Natl. Acad. Sci. USA 2014, 111, 14947-14952. [CrossRef] [PubMed]

34. Yong-Villalobos, L.; Gonzalez-Morales, S.I.; Wrobel, K.; Gutierrez-Alanis, D.; Cervantes-Perez, S.A.; Hayano-Kanashiro, C.; Oropeza-Aburto, A.; Cruz-Ramirez, A.; Martinez, O.; Herrera-Estrella, L. Methylome analysis reveals an important role for epigenetic changes in the regulation of the Arabidopsis response to phosphate starvation. Proc. Natl. Acad. Sci. USA 2015, 112, E7293-E7302. [CrossRef] [PubMed]

35. Niu, Y.F.; Chai, R.S.; Jin, G.L.; Wang, H.; Tang, C.X.; Zhang, Y.S. Responses of root architecture development to low phosphorus availability: A review. Ann. Bot. 2013, 112, 391-408. [CrossRef] [PubMed]

36. Péret, B.; Clement, M.; Nussaume, L.; Desnos, T. Root developmental adaptation to phosphate starvation: Better safe than sorry. Trends Plant Sci. 2011,16, 442-450. [CrossRef] [PubMed]

37. Wang, Y.L.; Almvik, M.; Clarke, N.; Eich-Greatorex, S.; Ogaard, A.F.; Krogstad, T.; Lambers, H.; Clarke, J.L. Contrasting responses of root morphology and root-exuded organic acids to low phosphorus availability in three important food crops with divergent root traits. AoB Plants 2015, 7, plv097. [CrossRef] [PubMed]

38. Bolouri-Moghaddam, M.R.; Le Roy, K.; Xiang, L.; Rolland, F.; Van den Ende, W. Sugar signalling and antioxidant network connections in plant cells. FEBS J. 2010, 277, 2022-2037. [CrossRef] [PubMed]

39. Lei, M.; Liu, Y.; Zhang, B.; Zhao, Y.; Wang, X.; Zhou, Y.; Raghothama, K.G.; Liu, D. Genetic and genomic evidence that sucrose is a global regulator of plant responses to phosphate starvation in Arabidopsis. Plant Physiol. 2011, 156, 1116-1130. [CrossRef] [PubMed]

40. Secco, D.; Jabnoune, M.; Walker, H.; Shou, H.; Wu, P.; Poirier, Y.; Whelan, J. Spatio-temporal transcript profiling of rice roots and shoots in response to phosphate starvation and recovery. Plant Cell 2013, 25, 4285-4304. [PubMed]

41. Deng, W.W.; Ogita, S.; Ashihara, H. Biosynthesis of theanine (gamma-ethylamino-L-glutamic acid) in seedlings of Camellia sinensis. Phytochem. Lett. 2008, 1, 115-119. [CrossRef]

42. Vuong, Q.V.; Bowyer, M.C.; Roach, P.D. L-Theanine: Properties, synthesis and isolation from tea. J. Sci. Food Agric. 2011, 91, 1931-1939. [CrossRef] [PubMed]

43. Liu, M.Y.; Burgos, A.; Ma, L.; Zhang, Q.; Tang, D.; Ruan, J. Lipidomics analysis unravels the effect of nitrogen fertilization on lipid metabolism in tea plant (Camellia sinensis L.). BMC Plant Biol. 2017, 17, 165. [CrossRef] [PubMed]

44. Aranjuelo, I.; Tcherkez, G.; Molero, G.; Gilard, F.; Avice, J.C.; Nogues, S. Concerted changes in N and C primary metabolism in alfalfa (Medicago sativa) under water restriction. J. Exp. Bot. 2013, 64, 885-897. [CrossRef] [PubMed] 
45. Vlad, F.; Spano, T.; Vlad, D.; Daher, F.B.; Ouelhadj, A.; Fragkostefanakis, S.; Kalaitzis, P. Involvement of Arabidopsis prolyl 4 hydroxylases in hypoxia, anoxia and mechanical wounding. Plant Signal Behav. 2007, 2, 368-369. [CrossRef] [PubMed]

46. Tannert, M.; May, A.; Ditfe, D.; Berger, S.; Balcke, G.U.; Tissier, A.; Köck, M. Pi starvation-dependent regulation of ethanolamine metabolism by phosphoethanolamine phosphatase PECP1 in Arabidopsis roots. J. Exp. Bot. 2018, 69, 467-481. [CrossRef] [PubMed]

47. Yin, R.; Messner, B.; Faus-Kessler, T.; Hoffmann, T.; Schwab, W.; Hajirezaei, M.R.; von Saint Paul, V.; Heller, W.; Schaffner, A.R. Feedback inhibition of the general phenylpropanoid and flavonol biosynthetic pathways upon a compromised flavonol-3-O-glycosylation. J. Exp. Bot. 2012, 63, 2465-2478. [CrossRef] [PubMed]

48. Yonekura-Sakakibara, K.; Tohge, T.; Matsuda, F.; Nakabayashi, R.; Takayama, H.; Niida, R.; Watanabe-Takahashi, A.; Inoue, E.; Saito, K. Comprehensive flavonol profiling and transcriptome coexpression analysis leading to decoding gene-metabolite correlations in Arabidopsis. Plant Cell 2008, 20, 2160-2176. [CrossRef] [PubMed]

49. Dai, X.; Zhuang, J.; Wu, Y.; Wang, P.; Zhao, G.; Liu, Y.; Jiang, X.; Gao, L.; Xia, T. Identification of a Flavonoid Glucosyltransferase Involved in 7-OH Site Glycosylation in Tea plants (Camellia sinensis). Sci. Rep. 2017, 7, 5926. [CrossRef] [PubMed]

50. Zhang, Q.; Shi, Y.; Ma, L.; Yi, X.; Ruan, J. Metabolomic analysis using ultra-performance liquid chromatography-quadrupole-time of flight mass spectrometry (UPLC-Q-TOF MS) uncovers the effects of light intensity and temperature under shading treatments on the metabolites in tea. PLOS ONE 2014, 9, e112572. [CrossRef] [PubMed]

51. Valluru, R.; Van den Ende, W. Myo-inositol and beyond-emerging networks under stress. Plant Sci. 2011, 181, 387-400. [CrossRef] [PubMed]

52. Donahue, J.L.; Alford, S.R.; Torabinejad, J.; Kerwin, R.E.; Nourbakhsh, A.; Ray, W.K.; Hernick, M.; Huang, X.; Lyons, B.M.; Hein, P.P.; et al. The Arabidopsis thaliana Myo-Inositol 1-Phosphate Synthase1 Gene Is Required for Myo-inositol Synthesis and Suppression of Cell Death. Plant Cell 2010, 22, 888-903. [CrossRef] [PubMed]

53. Meng, P.H.; Raynaud, C.; Tcherkez, G.; Blanchet, S.; Massoud, K.; Domenichini, S.; Henry, Y.; Soubigou-Taconnat, L.; Lelarge-Trouverie, C.; Saindrenan, P.; et al. Crosstalks between Myo-Inositol Metabolism, Programmed Cell Death and Basal Immunity in Arabidopsis. PLoS ONE 2009, 4, e7364. [CrossRef] [PubMed]

54. Foyer, C.H.; Parry, M.; Noctor, G. Markers and signals associated with nitrogen assimilation in higher plants. J. Exp. Bot. 2003, 54, 585-593. [CrossRef] [PubMed]

55. Novitskaya, L.; Trevanion, S.J.; Driscoll, S.; Foyer, C.H.; Noctor, G. How does photorespiration modulate leaf amino acid contents? A dual approach through modelling and metabolite analysis. Plant Cell Environ. 2002, 25, 821-835. [CrossRef]

56. Hernández, I.; Munné-Bosch, S. Linking phosphorus availability with photo-oxidative stress in plants. J. Exp. Bot. 2015, 66, 2889-2900. [CrossRef] [PubMed]

57. Aleksza, D.; Horvath, G.V.; Sandor, G.; Szabados, L. Proline Accumulation Is Regulated by Transcription Factors Associated with Phosphate Starvation. Plant Physiol. 2017, 175, 555-567. [CrossRef] [PubMed]

58. Cai, J.; Zeng, Z.; Connor, J.N.; Huang, C.Y.; Melino, V.; Kumar, P.; Miklavcic, S.J. RootGraph: A graphic optimization tool for automated image analysis of plant roots. J. Exp. Bot. 2015, 66, 6551-6562. [CrossRef] [PubMed]

59. Salahinejad, M.; Aflaki, F. Toxic and essential mineral elements content of black tea leaves and their tea infusions consumed in Iran. Biol. Trace Elem. Res. 2010, 134, 109-117. [CrossRef] [PubMed]

60. Liu, J.; Zhang, Q.; Liu, M.; Ma, L.; Shi, Y.; Ruan, J. Metabolomic Analyses Reveal Distinct Change of Metabolites and Quality of Green Tea during the Short Duration of a Single Spring Season. J. Agric. Food Chem. 2016, 64, 3302-3309. [CrossRef] [PubMed]

61. De Vos, R.C.; Moco, S.; Lommen, A.; Keurentjes, J.J.; Bino, R.J.; Hall, R.D. Untargeted large-scale plant metabolomics using liquid chromatography coupled to mass spectrometry. Nat. Protoc. 2007, 2, 778-791. [CrossRef] [PubMed]

62. Sumner, L.W.; Amberg, A.; Barrett, D.; Beale, M.H.; Beger, R.; Daykin, C.A.; Fan, T.W.; Fiehn, O.; Goodacre, R.; Griffin, J.L.; et al. Proposed minimum reporting standards for chemical analysis Chemical Analysis Working Group (CAWG) Metabolomics Standards Initiative (MSI). Metabolomics 2007, 3, 211-221. [CrossRef] [PubMed] 
63. Yuan, L.; Xiong, L.G.; Deng, T.T.; Wu, Y.; Li, J.; Liu, S.Q.; Huang, J.A.; Liu, Z.H. Comparative profiling of gene expression in Camellia sinensis L. cultivar AnJiBaiCha leaves during periodic albinism. Gene 2015, 561, $23-29$. [CrossRef] [PubMed]

64. Tao, S.; Li, J.; Gu, X.; Wang, Y.; Xia, Q.; Qin, B.; Zhu, L. Quantitative Analysis of ATP Sulfurylase and Selenocysteine Methyltransferase Gene Expression in Different Organs of Tea Plant (Camellia sinensis). Am. J. Plant Sci. 2012, 3, 51-59. [CrossRef]

65. Xiong, L.; Li, J.; Li, Y.; Yuan, L.; Liu, S.; Huang, J.; Liu, Z. Dynamic changes in catechin levels and catechin biosynthesis-related gene expression in albino tea plants (Camellia sinensis L.). Plant Physiol. Biochem. 2013, 71, 132-143. [CrossRef] [PubMed]

(C) 2018 by the authors. Licensee MDPI, Basel, Switzerland. This article is an open access article distributed under the terms and conditions of the Creative Commons Attribution (CC BY) license (http:/ / creativecommons.org/licenses/by/4.0/). 